\title{
MÉTODOS DE TALLA DE MASAS CENTRALES EN EL VALLE DEL RÍO CISNES (PATAGONIA CENTRO-OESTE) PARA DISCUTIR LA DISTRIBUCIÓN DE LAS ACTIVIDADES EN EL ESPACIO
}

\author{
BÁRBARA THOMPSONª \& CÉSAR MÉNDEZ ${ }^{b}$
}

\section{RESUMEN}

Se ha observado un uso redundante de diferentes ambientes a lo largo del valle del río Cisnes $\left(\sim 44^{\circ} \mathrm{S}\right)$, Patagonia centro oeste, a partir de 3.000 años cal. AP. Este artículo presenta un análisis de masas centrales líticas identificadas en la estepa y en los bosques caducifolios y siempreverdes, con el fin de determinar las diferencias y similitudes en los métodos de talla dentro de este marco temporal. Se definieron cuatro métodos de talla: el método inicial, el método de tendencia bifacial, el método multidireccional y el método de plataforma preferencial. Estas distinciones permiten discutir las diferencias entre los conjuntos tecnológicos de sitios residenciales y logísticos emplazados en los distintos sectores del valle. Concluimos que no existen diferencias cualitativas significativas en la distribución de los métodos de talla a lo largo del valle y que los cuatro métodos fueron comunes a los cazadores-recolectores que lo habitaron. Por lo tanto, los resultados obtenidos argumentan a favor de una organización común de la tecnología y saberes compartidos a lo largo de este eje de movilidad.

PALABRAS CLAVE: métodos de talla lítica, masas centrales, Holoceno tardío, Patagonia centro oeste, estepa, bosques.

\section{CORE AND CORE TOOL KNAPPING METHODS ACROSS THE CISNES RIVER VALLEY (CENTRAL WESTERN PATAGONIA) FOR DISCUSSING THE DISTRIBUTION OF ACTIVITIES ON THE LANDSCAPE}

\section{ABSTRACT}

A redundant use of different environment along the Cisnes river valley $\left(44^{\circ} \mathrm{S}\right.$ ) of Central Western Patagonia has been observed from $3000 \mathrm{cal}$. BP onwards. This paper presents an analysis of cores and core tools from sites in the steppe, deciduous and evergreen forests to ascertain differences and similarities in knapping methods within this time frame. Four knapping methods were defined across the studied sites of the valley: the initial method, the bifacial tendency method, the multidirectional

Caliboro 8939, La Reina, Santiago, Chile. \bthompsonpalma@gmail.com

b Centro de Investigación en Ecosistemas de la Patagonia. José de Moraleda 16, Coyhaique, Aisén, Chile.

cesar.mendez@ciep.cl 
method, and the preferential platform method. These allow discussing differences in the technological assemblages between residential and logistically oriented sites located across the valley. We conclude that there are no significant qualitative differences for explaining their distribution across the valley and that the four methods were common to hunter-gatherers who inhabited it. Thus, the results obtained argue in favor of a single-integrated technological organization and shared knowledge along this mobility axis.

KEY WORDS: lithic knapping methods, core and core tools, late Holocene, Central Western Patagonia, steppe, forests.

\section{INTRODUCCIÓN}

En la región de Aisén, el valle del río Cisnes $\left(\sim 44^{\circ} \mathrm{S}\right)$ representa un sector ideal para comprender la variabilidad de las ocupaciones humanas de Patagonia occidental, debido a que condensa una gradiente ecológica desde la estepa hasta los bosques a lo largo de un solo eje. Si bien la ocupación del valle se inició alrededor de 11.500 años atrás, y se registran ingresos puntuales a los bosques de la cuenca media alrededor de los 6.000 años cal. AP, es para momentos posteriores a los 23.000 años cal. AP, cuando se ha podido inferir una ocupación efectiva de sus distintos segmentos (Méndez et al. 2016a, 2016b). Se han definido ocupaciones de carácter residencial, principalmente emplazadas en la estepa, y en menor medida en zonas boscosas (Reyes et al. 2009). Dichos sitios se caracterizan por tener una relativa mayor extensión, la presencia de rasgos atribuidos a áreas de cocinas (rocas sometidas a combustión) y especialmente por presentar un registro lítico diverso, con amplia variedad de materias primas, cadenas operativas más completas y clases instrumentales relacionadas con actividades propias del ámbito doméstico (Reyes et al. 2006; Reyes et al. 2007b; Velásquez et al. 2007; Contreras et al. 2016). Por otro lado, se han identificado sitios de tarea sobre la base de las características más acotadas de su registro material, la baja diversidad de materias primas y la presencia de limitadas clases artefactuales (Reyes et al. 2006; Méndez et al. 2006a).

En ambos sectores del valle, bosques y estepas, así como en los distintos tipos de sitio, se identifican recurrentemente núcleos e instrumentos sobre núcleo. Los segundos fueron definidos preliminarmente como cepillos, asumiendo su rol en el descortezamiento y tratamiento de las superficies de maderas (Méndez et al. 2006a; Hormazábal, 2015; Contreras et al. 2016; Méndez et al. 2016a). Si bien no se cuenta con una asignación cronológica estricta para todos estos conjuntos, la tipología de materiales asociados, las edades disponibles en el valle (Méndez \& Reyes, 2006; Velásquez et al. 2007; Reyes et al. 2007b; Reyes et al. 2009; Méndez et al. 2016b; Méndez \& Nuevo-Delaunay, 2019) y su posición estratigráfica en sistemas de dunas (Méndez et al. 2019), sugieren que se tratarían de contextos del Holoceno tardío, probablemente posteriores a los 3.000 años cal. AP.

Al tallar un nódulo de materia prima lítica se generan dos productos, una masa central a la que se le extrae materia y la materia extraída en forma de lascas. Si el producto buscado para la manufactura de instrumentos son lascas, al nódulo se le denomina núcleo lítico y el proceso se conoce como debitage; pero si los instrumentos mismos son formatizados sobre el nódulo rocoso, el proceso se denomina façonnage (Inizan et al. 1999). Una masa central es el elemento céntrico final resultante (pieza descartada) del tallado de una porción de materia prima, independiente si la intención es el debitage para el desbaste de núcleos o el façonnage en la elaboración de instrumentos (Morello, 2005). Asimismo, porciones de materia prima generadas a partir de lascas de gran tamaño, de aquí en adelante entendidas como lascas masivas, pueden tomar el rol de una masa central al ser conceptualizada por el tallador como el elemento céntrico para realizar el debitage o el façonnage. Las piezas de este tipo han sido definidas con anterioridad como lascas espesas (Morello, 2005) y como lascas nodulares (Aschero, 1983).

Las masas centrales son testimonios muy informativos de los métodos de manufactura lítica ya que materializan las huellas del proceso de talla de los productos deseados y portan 
información sobre las secuencias y operaciones realizadas (Bleed, 2001; Pigeot, 2003; Morello, 2005). Los negativos de las extracciones, su orden y morfología, son testigos de las decisiones involucradas en la reducción de la materia prima $e$ indicadores de los procesos secuenciales que operaron en la manufactura. Es posible entender una parte importante de los sistemas tecnológicos mediante el estudio de los métodos de talla de las masas centrales.

$\mathrm{Si}$ consideramos que durante los últimos 3.000 años el espacio del valle del río Cisnes se jerarquizó diferencialmente, como lo sugiere la distribución de sitios residenciales y de tarea, así como la ocupación de ambientes abiertos (estepa y transición bosque-estepa) y cerrados (bosque), se espera que los métodos de talla puedan haber sido diferenciados de acuerdo con alguno de dichos ejes. Es por esto que planteamos las siguientes hipótesis. Hipótesis 0: no hubo diferenciación en los métodos de talla de masas centrales. Por lo tanto, la organización de las actividades del valle del río Cisnes fue indiferenciada (común a toda el área). Hipótesis 1a: hubo diferencias en los métodos de talla de masas centrales de acuerdo con los tipos de sitios. Por lo tanto, la organización espacial de las actividades a lo largo del valle fue una sola y varió en relación con la organización funcional de los asentamientos. Hipótesis 1b: hubo diferencias en los métodos de talla de masas centrales de acuerdo con el contexto ambiental. Por lo tanto, la organización espacial de las actividades fue diferente en el bosque y en la estepa, y los saberes tecnológicos fueron aplicados de manera selectiva en relación a los tipos de ambiente. En el caso de verificarse la Hipótesis 0 , se esperaría identificar los mismos métodos de talla replicándose de forma indiferenciada a lo largo de todo el valle del río Cisnes. En el caso de verificarse la Hipótesis 1a, esperaríamos diferentes métodos de talla según la función de sitio entre contextos de tareas y residenciales, $\mathrm{o}$, eventualmente, identificar variaciones dentro de cada método definido, motivadas por las actividades asociadas a los conjuntos. Finalmente, en el caso de verificarse la Hipótesis $1 b$, esto debería verse reflejado en diferentes métodos de talla entre ambientes cerrados (bosque caducifolio y siempreverde) y abiertos (estepa y transición bosque-estepa).

\section{ANTECEDENTES}

\section{Área de estudio: ambiente y paleoambiente}

El valle del río Cisnes $\left(\sim 44^{\circ} \mathrm{S}\right)$ se ubica en el norte de la región de Aisén (Chile). Esta hoya hidrográfica ocupa un lugar céntrico en el área continental de Patagonia occidental. Con una longitud de $160 \mathrm{~km}$ (Niemeyer \& Cereceda, 1984), el río Cisnes permite el tránsito desde la estepa hasta los tupidos bosques del oeste que caen directamente a los canales marinos del Pacífico. Producto del efecto orográfico, las precipitaciones acarreadas por los vientos del oeste se concentran en la cordillera de los Andes, descendiendo bruscamente en dirección al este (Garreaud, 2009). La geomorfología del valle se configura de oeste a este, en primer lugar, con la presencia de la Cordillera de los Andes, luego los Cordones Subandinos Orientales y, finalmente, los Relieves Planiformes Orientales (SERPLAC, 2005). La conjunción entre precipitaciones, orografía y temperatura da forma a tres ecorregiones principales (Quintanilla, 1984; Luebert \& Pliscoff, 2006): la ecorregión de estepa y transición bosqueestepa hacia el este, en la cuenca media contamos con la ecorregión de bosques caducifolios y para la cuenca inferior del valle, la ecorregión de los bosques siempreverdes.

Para efectos del presente trabajo, el área de estudio se dividió en dos subáreas principales, los ambientes abiertos y los cerrados. Los ambientes abiertos corresponden al área de estepa y transición bosque-estepa que se desarrolla principalmente en la cuenca superior del río Cisnes. Los ambientes cerrados, en cambio, se caracterizan por aquellas áreas de bosque caducifolio y bosque siempreverde, ubicados en las cuencas media e inferior del río, respectivamente (Fig. 1).

En cuanto al paleoambiente, luego del inicio de la deglaciación, desde los 19.000 años cal. AP en adelante (García et al. 2019), a los 14.600 años se dio un tránsito no gradual hacia condiciones de mayor humedad efectiva, llegando a un máximo en la extensión oriental de los bosques entre 8.000 y 3.000 años cal. AP (De Porras et al. 2012). Es precisamente hacia los 3.000 años cal. AP cuando se reconoce el advenimiento de condiciones de mayor aridez por espacio de $\sim 1.000$ años, 


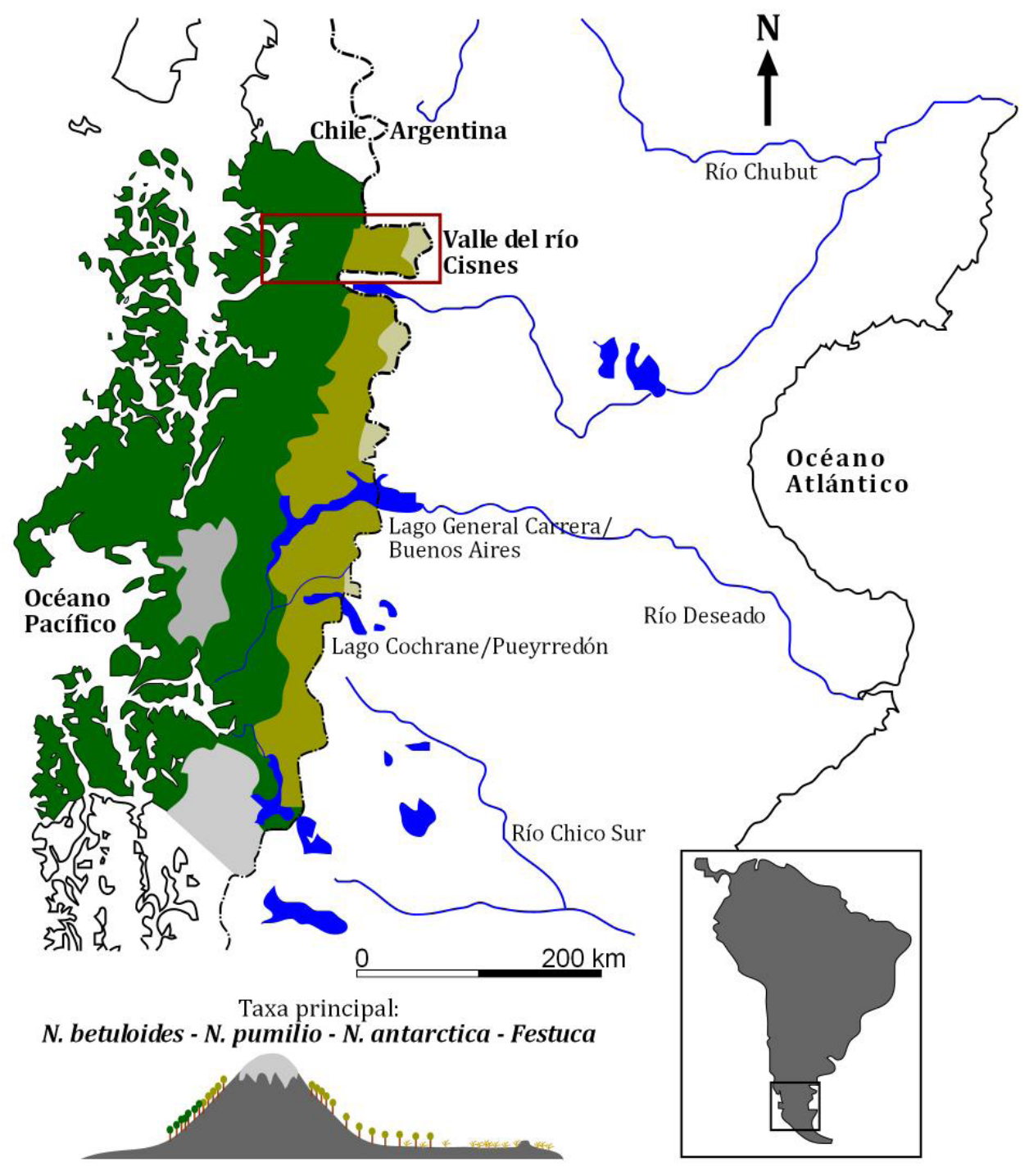

Bosque siempreverde $\square$ Bosque caducifolio $\square$ Estepa y ecotono bosque-estepa

Fig. 1. Región de Aisén, valle del río Cisnes y principales formaciones vegetacionales.

el retroceso de los bosques de Nothofagus e incremento en los patrones de fuego en sincronía con una ocupación de todos los segmentos del valle (De Porras et al. 2012, 2014; Méndez et al. 2016b).

\section{Ocupación humana}

Se ha planteado que la ocupación humana del oeste de Patagonia se configuró desde núcleos poblacionales centrados en las estepas orientales (Belardi \& Carballo, 2014; Borrero et al. 2019). Los bosques han sido descritos como un ambiente utilizado de manera estacional y logística que se complementa con medios esteparios más productivos (Borrero, 2004). Esto se sustenta a partir de las menores frecuencias de registro arqueológico y las características de los conjuntos materiales, los cuales presentan similitudes tipológicas con los de la estepa y materias primas 
alóctonas a las áreas de bosques (p.e. Carballido Calatayud, 2001; Bellelli et al. 2003; Belardi \& Carballo, 2014; Fernández \& Carballido Calatayud, 2015), además de motivos comunes en el arte rupestre registrado (Belardi \& Caracotche, 2005; Bellelli et al. 2008; Fernández et al. 2011; Méndez et al. 2016a). Estas evidencias asociadas con poblaciones esteparias permiten postular que los ambientes cerrados se utilizaron de manera articulada dentro de amplios rangos de movilidad. Se ha podido identificar que la intensidad del registro disminuye a medida que nos acercamos al oeste y nos alejamos de la estepa (Belardi et al. 2010), sugiriendo una menor intensidad y posible estacionalidad en el uso de los bosques.

En la región de Aisén se evidencia un registro puntual de sitios emplazados en ambientes cerrados, como, por ejemplo, Alero Las Quemas (Méndez \& Reyes, 2006), Cueva Las Guanacas (Mena, 1983) y Alero Fontana (Mena, 1992), con fechas cercanas a los $~ 6.000$ años cal. AP (Méndez et al. 2016a). Sobre la base de la baja productividad de los bosques y la presencia de similitudes tipológicas de los artefactos, se ha considerado que estas ocupaciones son complementadas con recursos y ocupaciones de ambientes esteparios (Reyes et al. 2009). Específicamente, el valle del río Cisnes registra una ocupación humana que inicia alrededor de los 11.500 años cal. AP (Méndez et al. 2016b). $\mathrm{Al}$ igual que en el resto de la región de Aisén, en los ambientes abiertos el registro arqueológico se presenta de manera intermitente a lo largo de todo el Holoceno (Méndez \& Reyes, 2008; Méndez et al. 2011, 2018). Para el caso de los bosques del Cisnes, es a partir de los 6.000 años cal. AP que se registra presencia humana en el sitio Alero Las Quemas (Méndez et al. 2016a). Hacia los 2.800 años cal. AP se tiene evidencia de sitios, tanto residenciales, como de tareas, en ambientes abiertos y cerrados, mostrándose por primera vez una contemporaneidad en la ocupación de distintos pisos altitudinales y vegetacionales dentro del valle (Reyes et al. 2009; Méndez et al. 2016b; Thompson \& Méndez, 2019). A pesar de no contar con una asignación cronológica para todas las ocupaciones, los conjuntos materiales comparten rasgos característicos (Méndez \& Reyes, 2006; Méndez et al. 2006a; Velásquez et al. 2007; Reyes et al. 2007b; Reyes et al. 2009), que, sumado a la posición estratigráfica de la mayoría de los sitios, permiten sugerir que el registro arqueológico fue depositado alrededor o después de esta fecha.

\section{METODOLOGÍA}

Este trabajo se enmarcó en una meso escala espacial definida por la extensión de la cuenca del río Cisnes y busca comparaciones en los conjuntos de masas centrales recuperadas a partir de los sitios identificados (Dincauze, 2002). La muestra corresponde a 75 masas centrales distribuidas en 20 sitios arqueológicos (Fig. 2, Tabla 1). Las piezas en estudio, en su mayoría, se registraron en superficie a excepción de aquellas identificadas en los sitios Alero El Chueco 1 y Alero Las Quemas.

Se analizó la secuencia y orden en que se realizó la talla lítica mediante la aplicación de esquemas diacríticos (Inizan et al. 1999). Se puso especial énfasis en realizar una clasificación del astillamiento tecnológico definiéndose aspectos como la organización de los negativos y su distribución en la pieza, así como también la descripción del soporte. Para esto se abordaron las siguientes categorías y variables (Odell, 1994; Andrefsky, 1998; Inizan et al. 1999; Pigeot, 2003; Morello, 2005): (1) Características del soporte como porcentaje de corteza, tipo de materia prima, volumen, atributos de las lascas masivas, erosión diferencial (Borrazzo, 2006) y estado de completitud de la pieza. (2) Técnica empleada, como el tipo de percusión, la presencia de acondicionamiento, y si se observa la preparación del borde adyacente a la(s) plataforma(s). Por tipo de percusión se buscó definir si la percusión aplicada fue dura o blanda. Esto se identificó sobre la base de las características de la materia prima, la forma de la extracción y las características morfológicas del negativo del bulbo identificado en las extracciones (Cotterell \& Kaaminga, 2000). Por otro lado, la preparación del borde adyacente a la plataforma de percusión refiere a las modificaciones para eliminar la cornisa dorsal y se observa a través de pequeños lascados adyacentes a la plataforma (Holdaway \& Stern, 2004). (3) Tipo y cantidad de plataformas de percusión. (4) Tipo de extracción, incluyendo el ángulo de extracción, la orientación de las extracciones según la morfología de la pieza y los planos de intersección de las superficies 


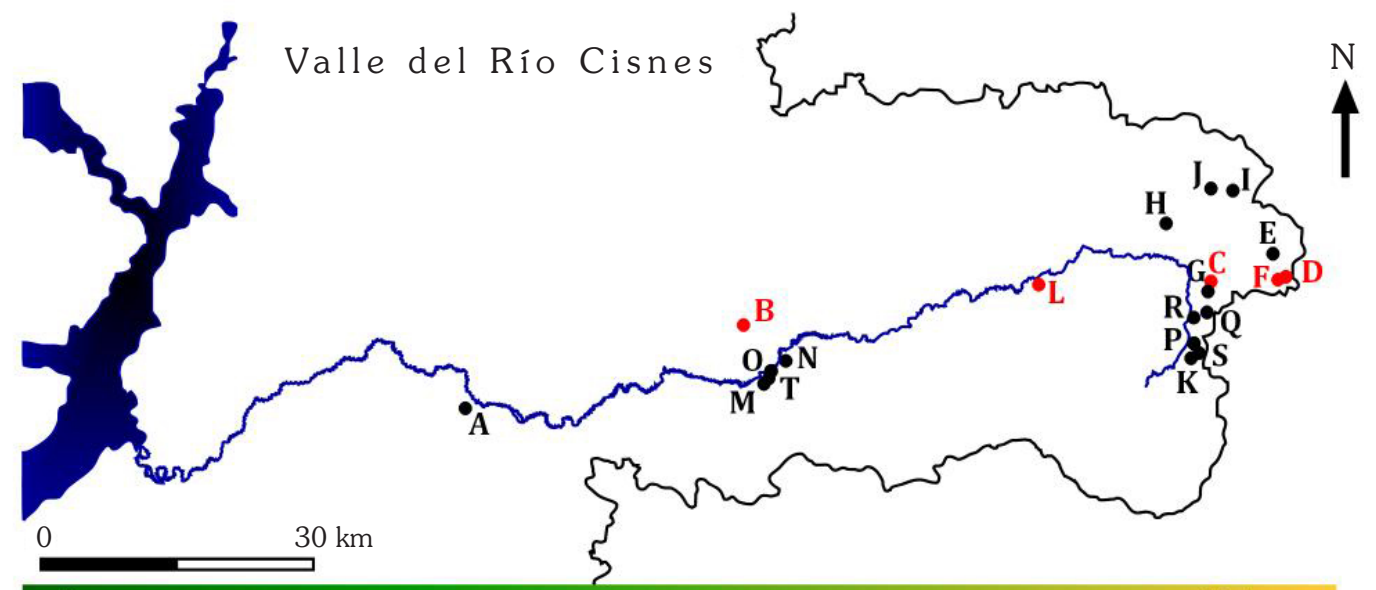

Bosque

Estepa

\begin{tabular}{r|r|} 
T: Río Moro & 1 \\
N: Altos del Moro 3 & 2 \\
M: Altos del Moro 2 & \\
O: Altos del Moro 1 \\
B: Las Quemas \\
A: El Toro
\end{tabular}

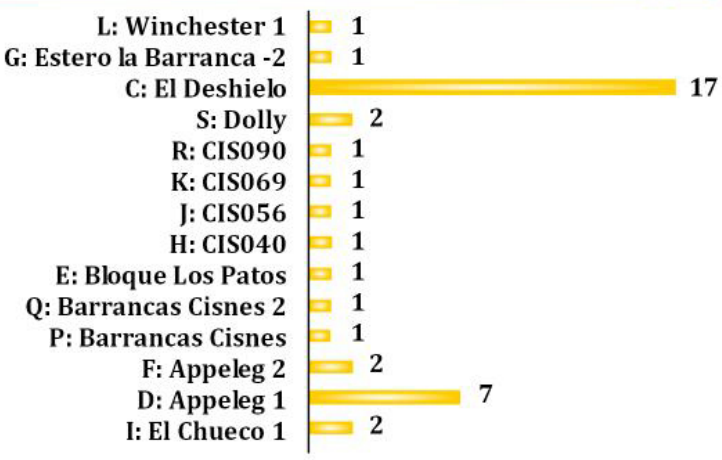

Fig. 2. Emplazamiento de sitios en estudio y frecuencia absoluta de masas centrales registradas.

(PIS) de desbaste y percusión, la extensión de las extracciones, y si su morfología era de tipo lasca o lámina.

Para definir la extensión de las extracciones se consideraron tres categorias: extracciones marginales, que abarcan hasta la mitad de la distancia entre el inicio de la extracción y el eje central de la superficie de desbaste; extracciones parcialmente extendidas, que llegan hasta el eje central sin sobrepasarlo $y$, finalmente, las extracciones extendidas como aquellas que sobrepasan la mitad del eje de la pieza.

El dibujo técnico se realizó en base a un lenguaje convencional, de acuerdo con las características de talla y morfología de la masa central. Estas características se relacionan con las extracciones, los ejes tecnológicos y de desbaste, y los planos de percusión presentes en las piezas según sea el caso. Hemos observado en la literatura una serie de formas de orientar las piezas que se configuran a partir de la conjunción entre aspectos funcionales y aquellos relacionados con la forma de talla. A modo de ejemplo, blade cores deben ser orientados con su plataforma de percusión en la parte superior, mientras que ciertos instrumentos, se sugiere que sean orientados con su filo activo hacia la parte superior, o incluso algunos a partir de su eje morfológico (Inizan et al. 1999). En este trabajo se decidió posicionar todas las piezas siguiendo su eje morfológico para analizar de manera transversal la muestra, evitando en primera instancia, clasificaciones en torno a la funcionalidad de los ejemplares, con el fin de centrarnos en las acciones que guiaron la talla lítica.

\section{RESULTADOS}

Si bien la frecuencia de sitios identificados disminuye a medida que nos adentramos en el valle hacia el oeste (Fig. 2), concentrándose las ocupaciones en los ambientes esteparios, la frecuencia de masas centrales aumenta. Es 
Tabla 1. Síntesis de los conjuntos líticos de sitios arqueológicos del valle del río Cisnes. R: residencial; L: logístico; EA: evento (de talla) aislado; AA: artefacto aislado. S/F: sin fechados. Curso bajo: bosque siempreverde; Curso medio: bosque caducifolio; Curso alto: estepa y transición bosque-estepa. *Corresponde a los niveles con masas centrales.

\begin{tabular}{|c|c|c|c|c|c|c|}
\hline Sitio & $\begin{array}{l}\text { Curso } \\
\text { del valle }\end{array}$ & $\mathrm{msnm}$ & Función & $\begin{array}{c}2 \sigma \\
\text { (años cal. AP) }\end{array}$ & Clases artefactuales líticas & Referencias \\
\hline Alero El Toro & Bajo & 377 & $\mathrm{~T}$ & $2.360-2.700$ & $\begin{array}{l}\text { Tajadores y cepillos, talla } \\
\text { bifacial, láminas, núcleos, } \\
\text { percutor, mano de moler }\end{array}$ & $\begin{array}{l}\text { Bate \& Mena, 2005; } \\
\text { Méndez et al. 2006b; } \\
\text { Méndez et al. 2016b }\end{array}$ \\
\hline $\begin{array}{l}\text { Alero Las } \\
\text { Quemas }\end{array}$ & Medio & 710 & $\mathrm{R}$ & $\begin{array}{l}5.990-6.270 \\
\text { y } 2.200- \\
3.040\end{array}$ & $\begin{array}{l}\text { Lascas de retoque marginal, } \\
\text { láminas, raspador, núcleo, } \\
\text { mano de moler, cepillo. }\end{array}$ & $\begin{array}{l}\text { Méndez \& Reyes, 2006; } \\
\text { Méndez et al. 2016a; } \\
\text { Méndez et al. 2016b }\end{array}$ \\
\hline $\begin{array}{l}\text { El Deshielo } \\
\text { (CIS 008) }\end{array}$ & Alto & 986 & $\mathrm{R}$ & $3.000-3.230$ & $\begin{array}{l}\text { Bolas, cepillos, núcleos, } \\
\text { láminas y lascas retocadas, } \\
\text { machacador, manos de } \\
\text { moler, percutor, bifaz, } \\
\text { raedera, raspadores, puntas } \\
\text { de proyectil. }\end{array}$ & $\begin{array}{l}\text { Reyes et al. 2006; Reyes } \\
\text { et al. 2009; Méndez et } \\
\text { al. 2010; Contreras et al. } \\
\text { 2016; Méndez et al. } 2019\end{array}$ \\
\hline $\begin{array}{l}\text { Appeleg } 1 \\
\text { (CIS 009) }\end{array}$ & Alto & 902 & $\mathrm{R}$ & $\begin{array}{c}330-500 y \\
730-800\end{array}$ & $\begin{array}{l}\text { Bifaz, bolas, cepillo, núcleos, } \\
\text { cuchillos, cuenta, láminas } \\
\text { y lascas retocadas, lito } \\
\text { discoidal, percutor, puntas } \\
\text { de proyectil, raederas, } \\
\text { raspadores. }\end{array}$ & $\begin{array}{c}\text { Reyes et al. 2006; } \\
\text { Velásquez et al. 2007; } \\
\text { Contreras et al. 2016; } \\
\text { Méndez et al. 2016b; } \\
\text { Méndez \& Nuevo-Delaunay, } \\
2019\end{array}$ \\
\hline $\begin{array}{l}\text { Bloque Los } \\
\text { Patos (CIS } \\
012 \text { ) }\end{array}$ & Alto & 904 & $\mathrm{~T}$ & $\mathrm{~S} / \mathrm{F}$ & $\begin{array}{l}\text { Lascas de producción } \\
\text { bifacial y bifaz. }\end{array}$ & Reyes et al. 2006 \\
\hline $\begin{array}{l}\text { Appeleg } 2 \\
\text { (CIS 018) }\end{array}$ & Alto & 915 & $\mathrm{R}$ & $\mathrm{S} / \mathrm{F}$ & $\begin{array}{l}\text { Boleadora, núcleos, } \\
\text { láminas y lascas retocadas, } \\
\text { preforma, raspadores. }\end{array}$ & $\begin{array}{l}\text { Reyes et al. 2006; } \\
\text { Velásquez et al. 2007; } \\
\text { Contreras et al. } 2016\end{array}$ \\
\hline $\begin{array}{l}\text { E. La Barranca } \\
-2 \text { (CIS 020) }\end{array}$ & Alto & 1000 & $\mathrm{~T}$ & $\mathrm{~S} / \mathrm{F}$ & $\begin{array}{l}\text { Concentración lítica, núcleo, } \\
\text { lascas. }\end{array}$ & Reyes et al. 2006 \\
\hline $\begin{array}{l}\text { Sin nombre } \\
\text { (CIS 040) }\end{array}$ & Alto & 789 & $\mathrm{~T}$ & $\mathrm{~S} / \mathrm{F}$ & $\begin{array}{l}\text { Concentración de material } \\
\text { lítico, núcleo y lascas. }\end{array}$ & Reyes et al. 2006 \\
\hline $\begin{array}{l}\text { El Chueco } 1 \\
\text { (CIS 042) }\end{array}$ & Alto & 915 & $\mathrm{~T}$ & $\begin{array}{l}2.350-2.710 \\
2.990-3.210 \\
5.590-5.720^{*}\end{array}$ & $\begin{array}{l}\text { Bola, percutor, cepillo, } \\
\text { denticulado, bifaciales, hojas, } \\
\text { lasca retocada, raspador, } \\
\text { nódulo astillado, raedera, } \\
\text { núcleo, lascas. }\end{array}$ & $\begin{array}{l}\text { Méndez et al. 2011; } \\
\text { Méndez et al. 2016b }\end{array}$ \\
\hline $\begin{array}{l}\text { Sin nombre } \\
\text { (CIS 056) }\end{array}$ & Alto & 837 & $\mathrm{~T}(\mathrm{EA})$ & $\mathrm{S} / \mathrm{F}$ & Núcleo y lascas & Este trabajo \\
\hline $\begin{array}{l}\text { Sin nombre } \\
\text { (CIS 069) }\end{array}$ & Alto & 1067 & $\mathrm{~T}(\mathrm{AA})$ & $\mathrm{S} / \mathrm{F}$ & Núcleo & Este trabajo \\
\hline $\begin{array}{l}\text { Winchester } 1 \\
\text { (CIS 077) }\end{array}$ & Alto & 656 & $\mathrm{R}$ & $680-770$ & $\begin{array}{l}\text { Bolas líticas, manos de } \\
\text { moler, instrumentos } \\
\text { sobre núcleo, raspadores, } \\
\text { sobadores, cuchillos } \\
\text { bifaciales, cepillos sobre } \\
\text { guijarro o tajadores, láminas } \\
\text { y lascas. }\end{array}$ & $\begin{array}{l}\text { Reyes et al. 2007b; } \\
\text { Reyes et al. 2009; } \\
\text { Méndez et al. 2016b }\end{array}$ \\
\hline $\begin{array}{l}\text { Altos del Moro } \\
2 \text { (CIS 079) }\end{array}$ & Medio & 535 & $\mathrm{~T}$ & $1.730-2.000$ & $\begin{array}{l}\text { Percutores, cepillos, núcleos, } \\
\text { raedera, láminas y lascas. }\end{array}$ & $\begin{array}{l}\text { Thompson \& Méndez, } \\
2019\end{array}$ \\
\hline
\end{tabular}


Continuación Tabla 1.

\begin{tabular}{|c|c|c|c|c|c|c|}
\hline Sitio & $\begin{array}{l}\text { Curso } \\
\text { del valle }\end{array}$ & msnm & Función & $\begin{array}{c}2 \sigma \\
\text { (años cal. AP) }\end{array}$ & Clases artefactuales líticas & Referencias \\
\hline $\begin{array}{l}\text { Altos del Moro } \\
3 \text { (CIS 080) }\end{array}$ & Medio & 599 & $\mathrm{~T}(\mathrm{EA})$ & $\mathrm{S} / \mathrm{F}$ & $\begin{array}{l}\text { Concentración de material } \\
\text { lítico, núcleo y lascas. }\end{array}$ & Este trabajo \\
\hline $\begin{array}{l}\text { Altos del Moro } \\
1 \text { (CIS 081) }\end{array}$ & Medio & 533 & $\mathrm{~T}$ & $5.650-5.890$ & Raspador, cepillos y lascas. & Este trabajo \\
\hline $\begin{array}{l}\text { Barrancas } \\
\text { Cisnes (CIS } \\
085 \text { ) }\end{array}$ & Alto & 1044 & $\mathrm{~T}$ & $\mathrm{~S} / \mathrm{F}$ & Cepillo, derivados de núcleo. & Este trabajo \\
\hline $\begin{array}{l}\text { Barrancas } \\
\text { Cisnes } 2 \text { (CIS } \\
\text { 087) }\end{array}$ & Alto & 1010 & $\mathrm{~T}$ & $\mathrm{~S} / \mathrm{F}$ & $\begin{array}{l}\text { Núcleo, percutor, derivados } \\
\text { núcleo, desechos talla. }\end{array}$ & Este trabajo \\
\hline $\begin{array}{l}\text { Sin nombre } \\
\text { (CIS 090) }\end{array}$ & Alto & 1054 & $\mathrm{~T}$ & $\mathrm{~S} / \mathrm{F}$ & $\begin{array}{l}\text { Concentración de material } \\
\text { lítico, cepillo. }\end{array}$ & Este trabajo \\
\hline $\begin{array}{l}\text { Dolly (CIS } \\
\text { 098) }\end{array}$ & Alto & 1025 & $\mathrm{~T}$ & $\mathrm{~S} / \mathrm{F}$ & $\begin{array}{l}\text { Núcleo, cepillo, derivados de } \\
\text { núcleo, desechos de talla }\end{array}$ & Este trabajo \\
\hline Río Moro & Medio & 538 & $\mathrm{~T}(\mathrm{AA})$ & $\mathrm{S} / \mathrm{F}$ & Núcleo & Este trabajo \\
\hline
\end{tabular}

decir, la muestra se compone de 39 piezas en los ambientes abiertos y 36 piezas en ambientes cerrados. Si esto lo relacionamos con la cantidad de sitios arqueológicos en estudio, contamos con un promedio de 6,0 piezas por sitio en ambientes cerrados, mientras que en ambientes abiertos es de 2,8 piezas por sitio.

\section{Métodos de talla}

Fruto del análisis diacrítico aplicado a las piezas fue posible definir un número de cuatro métodos de talla: el método inicial, el método de tendencia bifacial, el método multidireccional y el método de plataforma preferencial (Thompson, 2016).

(1) Método de talla inicial

Este método fue definido a partir del 5,3\% de la muestra $(n=4)$. Consiste en la remoción de un número reducido de extracciones que no se organizan según un plan guía de talla aparente (Fig. 4). En todos los casos identificados, el número de extracciones observado es reducido y la calidad de la materia prima transita de regular a mala, por lo que se sostiene que las evidencias

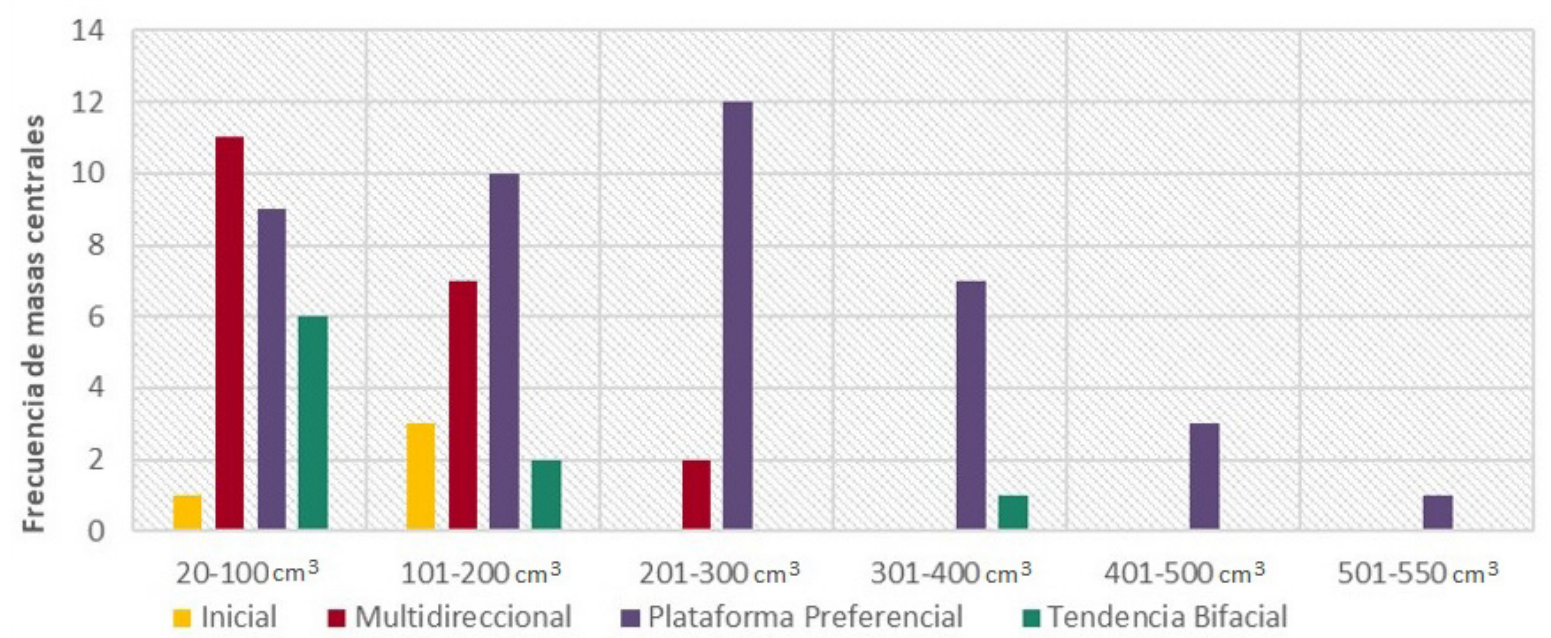

Fig. 3. Volúmenes $\left(\mathrm{cm}^{3}\right)$ de las piezas en estudio según método de talla identificado. 


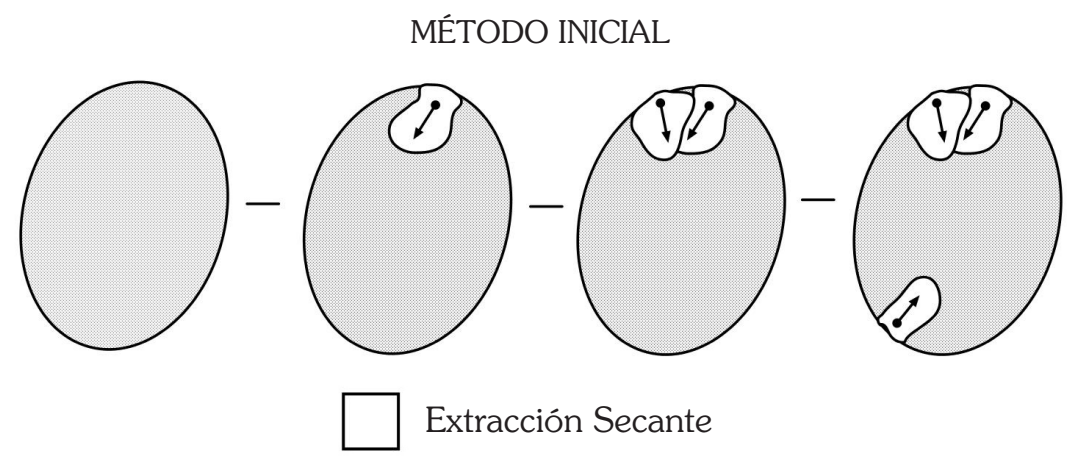

Fig. 4. Representación esquemática del método de talla inicial.

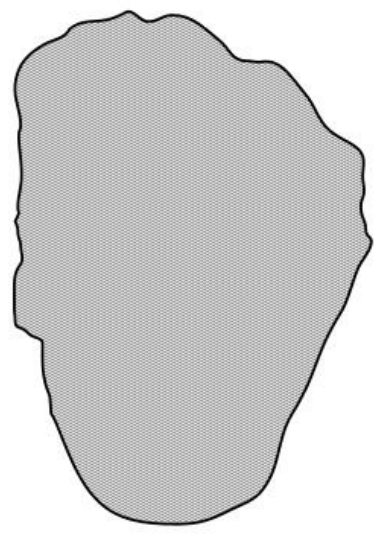

Cortex

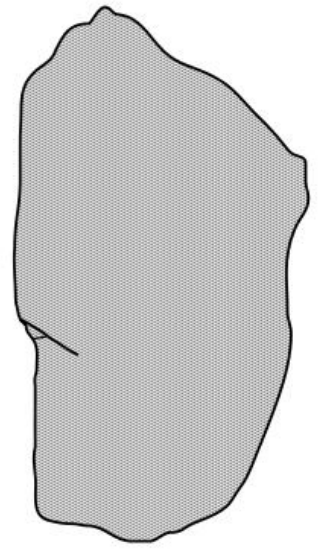

0

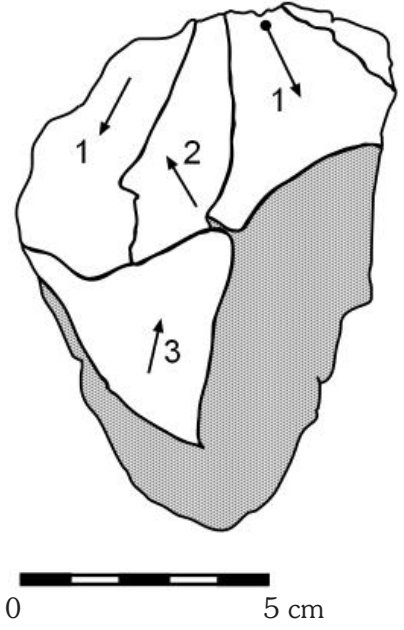

$5 \mathrm{~cm}$

$\longrightarrow$ Dirección de la extracción, punto indica contrabulbo

$\longrightarrow$ Dirección de la extracción

Fig. 5. Ejemplar ilustrativo del método de talla inicial. El Chueco 1 (CIS042; estepa).

corresponden a pruebas de la calidad de los nódulos rechazados. En estos casos, las piezas mantienen gran parte del volumen original del soporte y cuentan con algún porcentaje de corteza. La técnica de aplicación de la fuerza es principalmente percusión dura, observándose una tendencia general a la percusión aleatoria y arbitraria del núcleo (Fig. 5). La morfología de todas las extracciones corresponde a lascas y no se observa una predeterminación en la forma de los productos.

\section{Método de talla de tendencia bifacial}

Todas aquellas piezas, $12 \%(\mathrm{n}=9)$, en donde la intersección entre la plataforma de desbaste y la plataforma de percusión es coincidente con el plano de intersección de las superficies, fueron clasificadas como talladas según el método de tendencia bifacial (Fig. 6, Fig. 7). En estos casos, las piezas cuentan con dos superficies en donde ambas caras cumplen el rol tanto de plataforma de percusión, como de desbaste. Presentan características de talla bifacial y son similares a los métodos discoidal, inclinado y bisecante, identificados en la literatura (p.e. Böeda, 1993, 1995; Conard et al. 2004; Loyola et al. 2018), y en algunos casos encontramos características de los núcleos paralelos, observándose extracciones paralelas al plano de intersección de las superficies (p.e. Bordes, 1961; Conard et al. 2004).

La morfología de las piezas tiende a una forma cónica o bicónica, en donde las extracciones 


\section{MÉTODO DE TENDENCIA BIFACIAL}

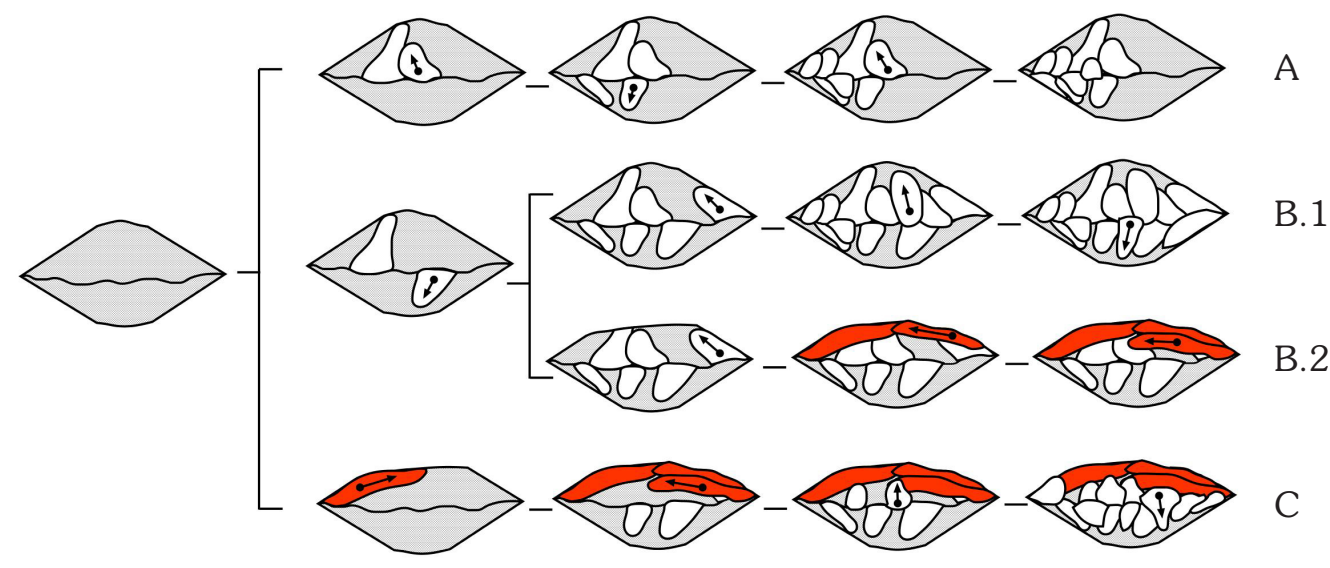

La intersección entre la plataforma principal de percusión y la superficie de desbaste es igual al plano de intersección de las superficies (PIS)

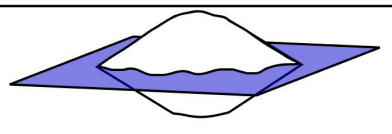

Extracciones paralelas en relación al PIS

Extracciones secantes en relación al PIS

Fig. 6. Representación esquemática del método de talla de tendencia bifacial. A: talla bifacial de dirección centrípeta, concentrada en sólo una porción del filo de la pieza, los productos corresponden a lascas. B.1: piezas talladas bifacialmente de manera completamente centrípeta-radial, productos de morfología de lasca. B.2: se talla la pieza bajo una lógica centrípeta-radial generándose lascas como productos, y en una segunda fase se extraen productos laminares tendientes a la unidireccionalidad. C: extracciones laminares unidireccionales a las cuales se le superponen extracciones centrípetas radiales con morfología de lascas.

observadas son del tipo secantes, con ángulo $\sim 45^{\circ}$, y paralelas, con un ángulo igual o menor a $30^{\circ}$ en relación con el plano de intersección de las superficies. Se decidió agrupar las piezas que presentaron extracciones tanto paralelas como secantes bajo un mismo método, debido a que la concepción volumétrica de la pieza y las acciones técnicas de su talla son bastante similares.

Las materias primas de las piezas corresponden a seis tipos, de los cuales un $66,6 \%$ son tobas y andesitas, entre ellas una variedad de toba que sufre un proceso de producción acelerado de neocórtex. El resto (tres variedades de materias primas) representa el $33,3 \%$, destacando una masa central de sílice de muy buena calidad (Fig. 7). En general, los soportes tienden a ser de tamaños pequeños y algunos se muestran prácticamente agotados. Sus volúmenes están en el rango entre 20 y $200 \mathrm{~cm}^{3}$. Sólo un ejemplar tiene un volumen de $400 \mathrm{~cm}^{3}$, tamaño que resalta dentro del conjunto en estudio (Fig. 3).
Se observó la aplicación de tres técnicas en este método de talla. Por una parte, se identificó el uso de percusión dura en un $77,8 \%$ de los ejemplares y un $22,2 \%$ de percusión blanda. Por otro lado, observamos que al $66,7 \%$ de las piezas se le aplicó una preparación del borde adyacente a la plataforma. El número de plataformas en todos los casos es dos y tiene relación con la característica dual que tienen ambas caras de la pieza. La plataforma de percusión es a la vez plataforma de desbaste de su cara opuesta y viceversa.

Un $44,4 \%$ de las piezas presenta sólo extracciones secantes, mientras que en un $55,6 \%$ se observan tanto extracciones secantes como paralelas al plano de intersección de las superficies. La orientación de las extracciones es principalmente radial o centrípeta. Finalmente, el tipo de producto que se buscó mayormente fueron lascas, a excepción de dos casos en los que se observó la extracción de lascas y láminas en una misma pieza (Fig. 7). 
A
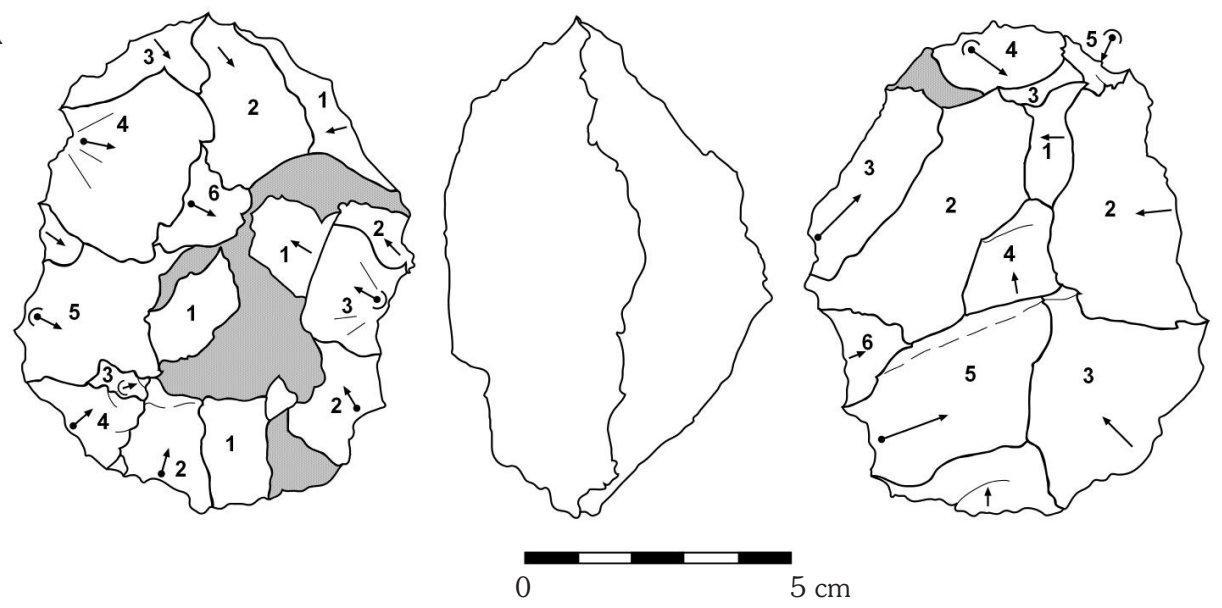

B
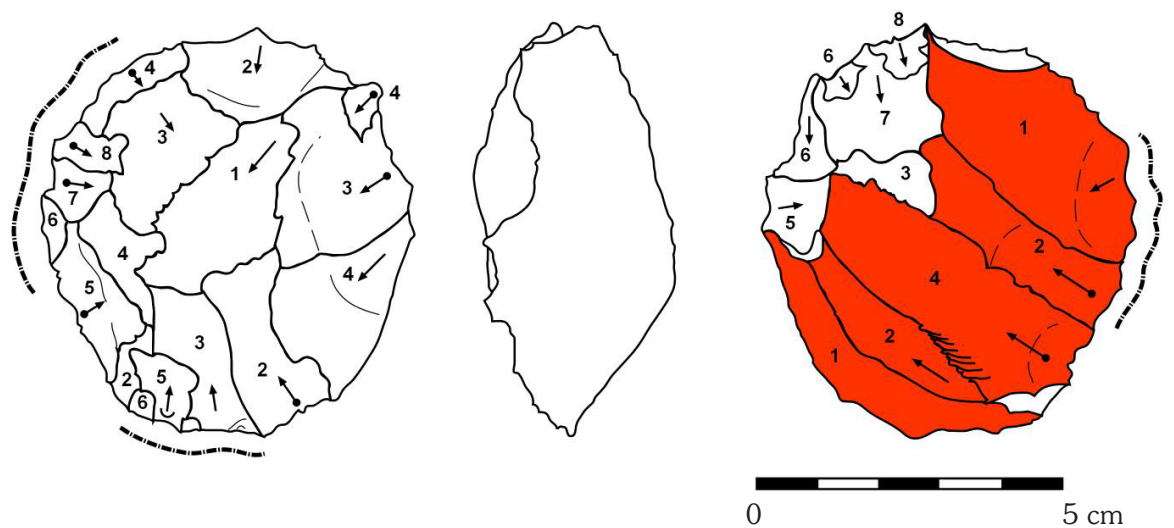

$\longrightarrow$ Preparación del borde adyacente a la plataforma (PBAP)
$\longrightarrow$ Dirección de la extracción, punto indica contrabulbo
$\square$ Dirección de la extracción
$\begin{aligned} & \text { Extracciones paralelas al plano de intersección de las superficies } \\ & \text { Cortex }\end{aligned}$

Fig. 7. Piezas talladas según el método de tendencia bifacial. A: Río Moro (bosque caducifolio). B: El Deshielo (CIS008; estepa). Materia prima silícea de buena calidad. Se observa una mayor inversión de energía, presenta extracciones de tipo laminar y lascas.

\section{(3) Método de talla multidireccional}

El $26,7 \% \quad(n=20)$ del conjunto total corresponde a piezas que no cuentan con una plataforma de desbaste bien definida, tienden a formas diversas y fueron talladas siguiendo una lógica de múltiples direcciones (Fig. 8). Éstas permitieron definir la presencia del método de talla multidireccional (p.e. Inizan et al. 1999; Conard et al. 2004).
En cuanto a la materia prima de los ejemplares, un $40 \%$ corresponde a rocas basálticas y andesíticas, y un $45 \%$ a rocas silíceas, mientras que el $15 \%$ restante corresponde a meterías primas variadas. Resalta que del total de masas centrales de materias primas silíceas identificadas en el valle $(n=13)$, el $69,2 \%(n=9)$ fue tallado según este método. Los soportes tienen volúmenes entre 20 y $100 \mathrm{~cm}^{3}$, siendo bastante pequeños en comparación con el resto 


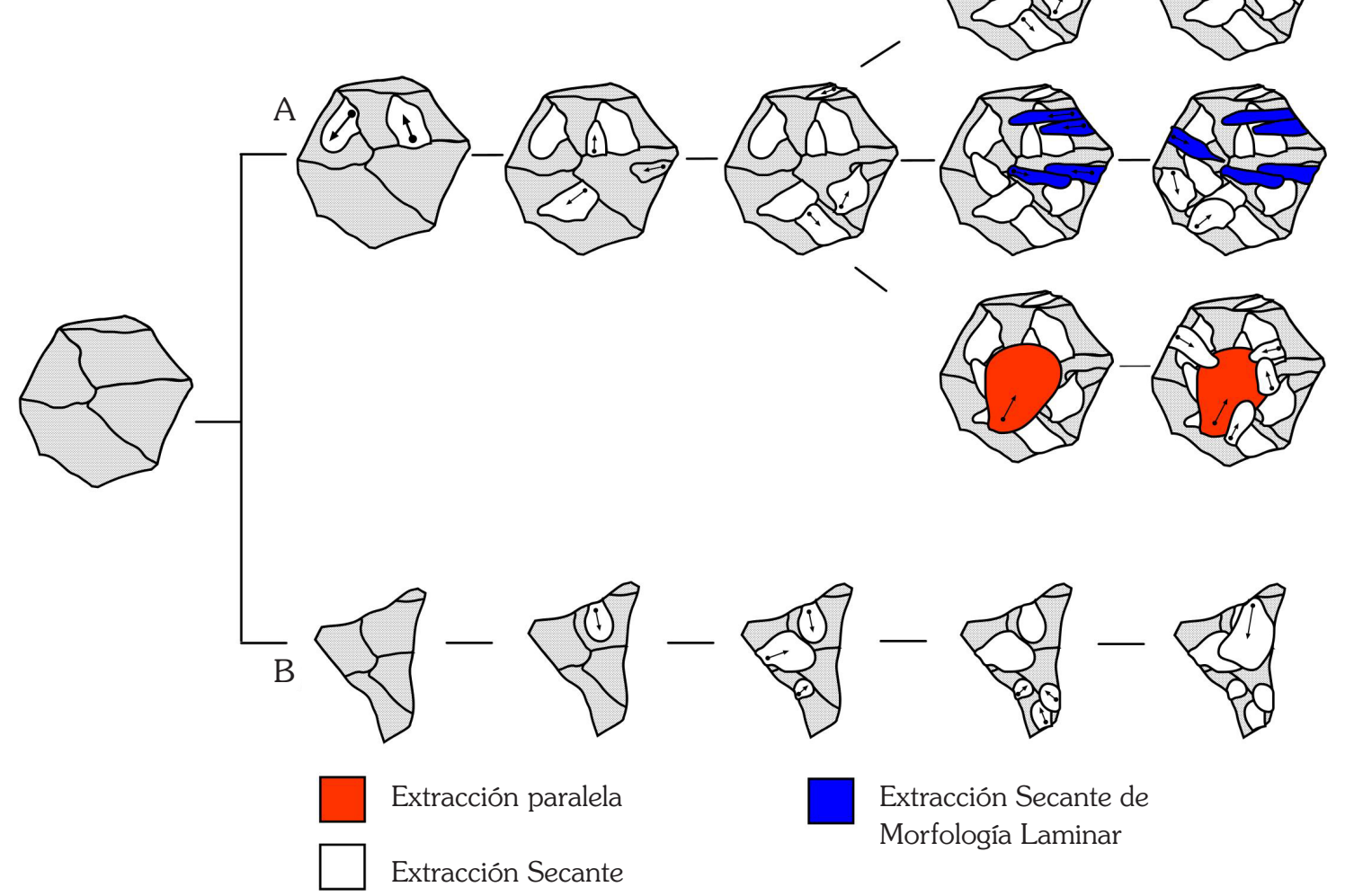

Fig. 8. Representación esquemática del método de talla multidireccional. A: soportes de apariencia poliédrica. B: matriz fracturada utilizada como soporte.

de las masas centrales estudiadas. En general las piezas, o no presentan corteza, o figuran con un porcentaje bajo que va entre 0 y el $25 \%$ (Fig. 9). Se observó el uso de tres técnicas de talla, percusión dura, blanda y preparación del borde adyacente a la plataforma. Destaca que en el $85 \%(n=17)$ de las piezas se usó percusión dura y en un $30 \%(n=6)$ se identificó la preparación del borde adyacente a la plataforma. Como superficie de percusión se utilizó la superficie de desbaste, observándose la ausencia de plataformas definidas. La dirección de las extracciones en la mayoría de los casos es multidireccional y la extensión de las extracciones es parcialmente extendida $y$ extendida; a excepción de un $10 \%$ de las piezas en las que se identifican extracciones marginales en conjunto con las otras dos (Fig. 8).
(4) Método de talla de plataforma preferencial

Se ha caracterizado como parte del método de talla de plataforma preferencial a todas las piezas que cuentan con una o más plataformas principales de percusión. En el caso de este método, el plano de intersección de las superficies es coincidente con la plataforma de percusión y las extracciones cuentan con un ángulo de remoción mayor a los $45^{\circ}$ y cercano a los $90^{\circ}$ (Fig. 10). Corresponde, por una parte, a lo definido por Conard et al. (2004) como núcleo de plataforma y, por otra, al método de desbaste unipolar secante simple descrito por Loyola et al. (2018). Dentro de esta categoría se concentra el $56 \%(n=42)$ de las masas centrales del valle.

En el caso de este método, se identificaron ejemplares de todas las materias primas reconocidas en la muestra de estudio, a excepción de la obsidiana 
A

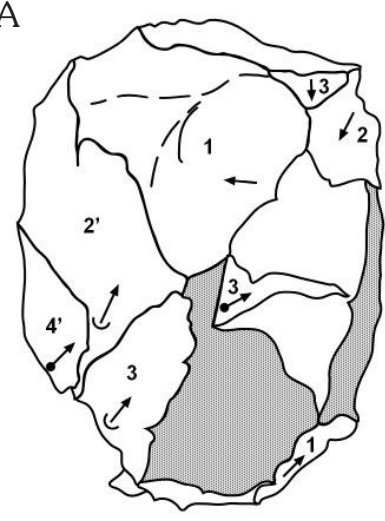

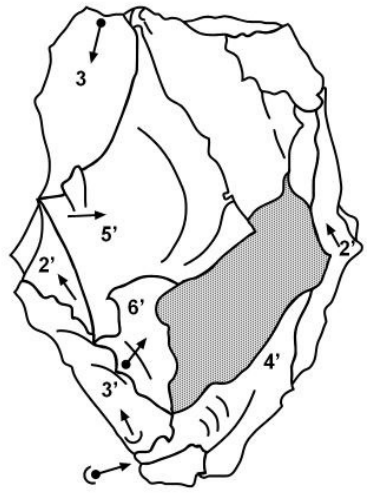

$5 \mathrm{~cm}$
B
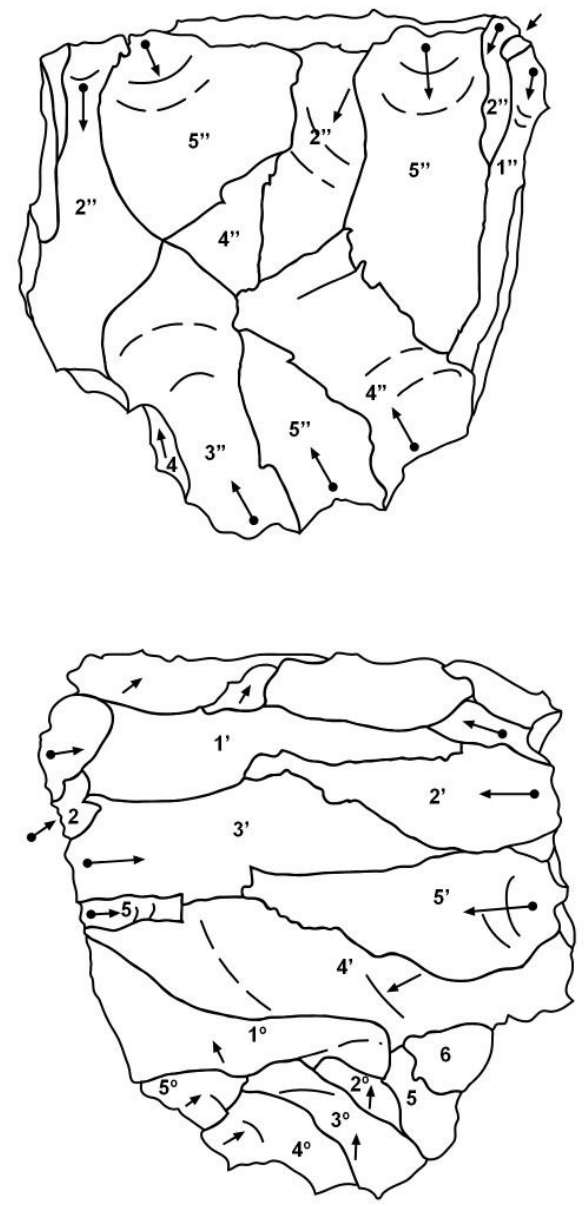

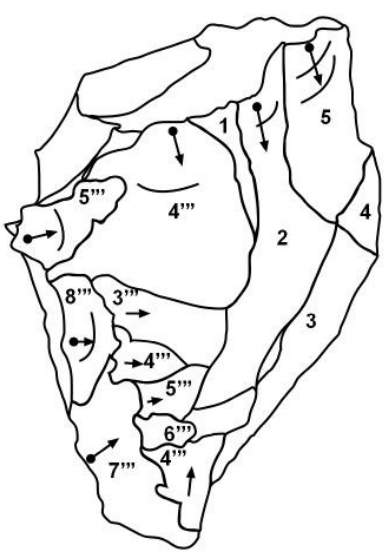

$\square$ Cortex

$\longrightarrow$ Dirección de la extracción , punto indica contrabulbo

$\longrightarrow$ Dirección de la extracción

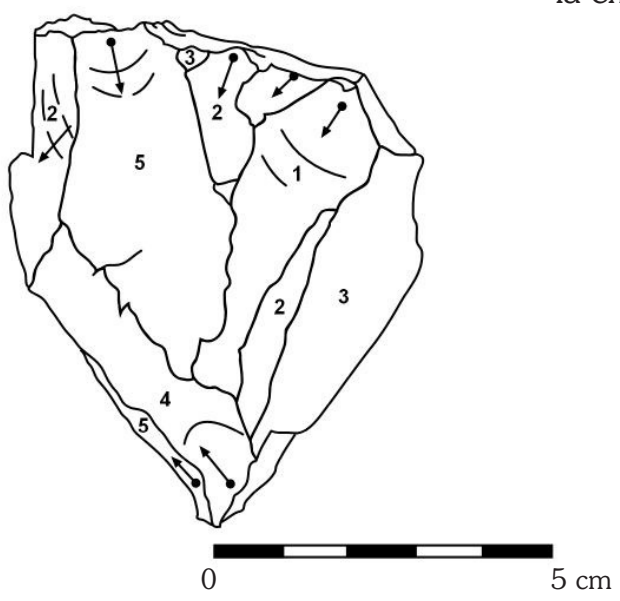

Fig. 9. Piezas talladas según el método multidireccional. A: Alero Las Quemas (bosque caducifolio). B: Appeleg 1 (CIS009; estepa). Esta pieza es una variante dentro del método de talla multidireccional. Se identifica una acción de tallar normada, si bien se observa una multidireccionalidad a nivel general, se utilizan plataformas de percusión en cada una de las caras virtuales de la pieza. 


\section{MÉTODO DE PLATAFORMA PREFERENCIAL}
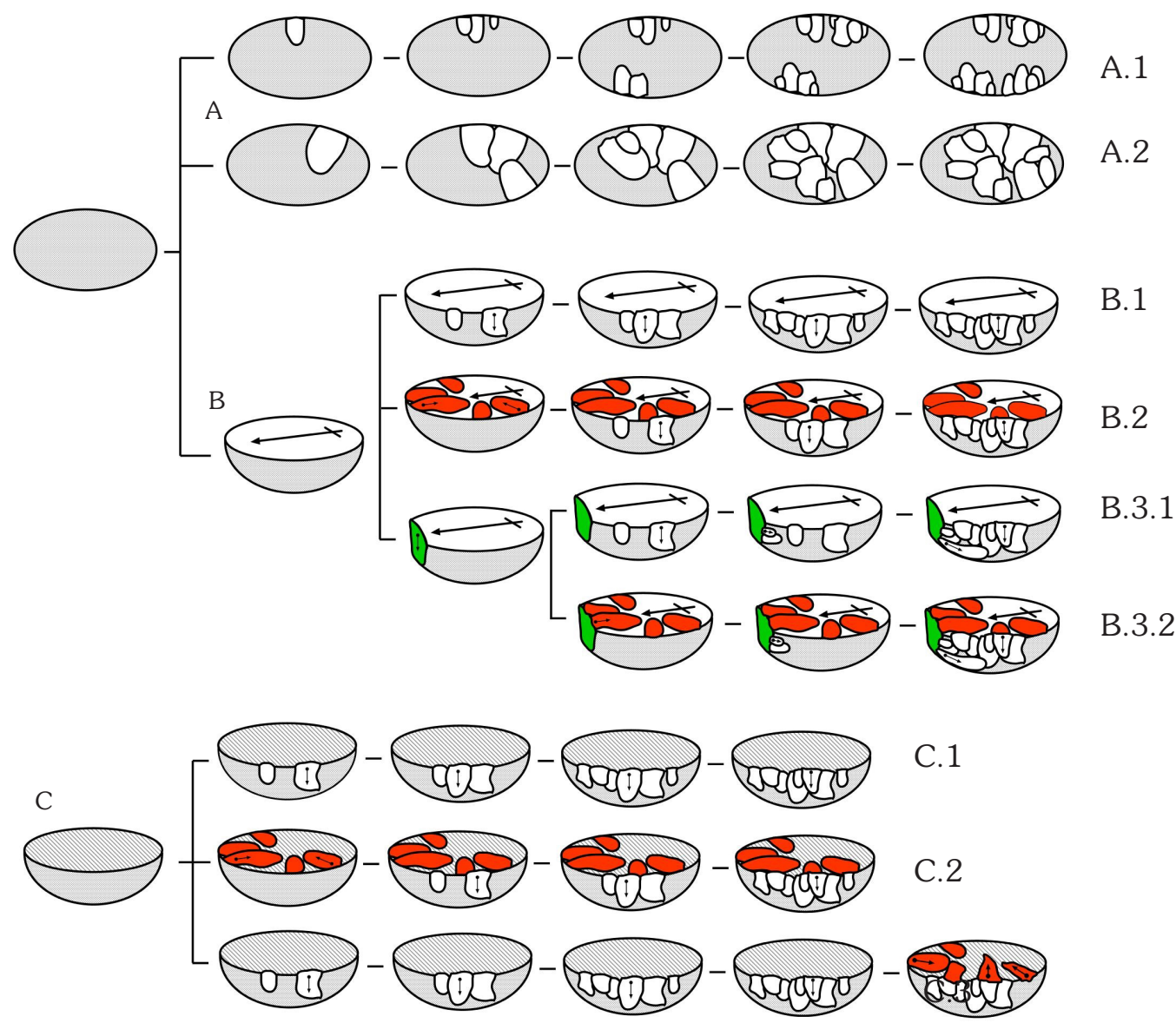

PIS: Plano de Intersección de las Superficies PPP: Plataforma Principal de Percusión

Extracción Paralela en relación al PIS

Extracción Secante en relación al PIS
Plataforma Secundaria

A: Plataformas corticales

B: Plataformas sobre Lasca Masiva

C: Plataformas Planas Naturales

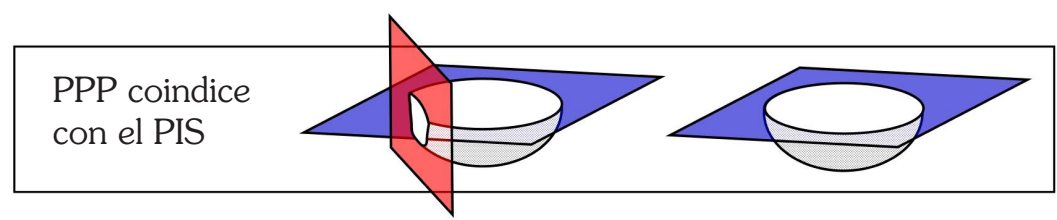

Fig. 10. Resumen esquemático del método de talla de plataforma preferencial. A: plataformas corticales. A.1: aprovechamiento de piezas que naturalmente cuenten con dos plataformas, generándose extracciones unidireccionales opuestas.

A.2: extracciones realizadas sobre el contorno del guijarro. B: plataformas sobre reverso de lasca masiva. B.1: extracciones secantes en relación al PIS. B.2: extracciones paralelas al PIS y sobre éstas, extracciones secantes al PIS. B.3: dos o más plataformas de percusión. B.3.1: extracciones secantes. B.3.2: extracciones paralelas y luego secantes. C: plataformas planas naturales, planos de debilidad de la materia como plataformas de percusión. C.1: extracciones secantes al PIS. C.2: extracciones paralelas al PIS y luego secantes. C.3: extracciones secantes al PIS y sobre éstas, paralelas al PIS. 
local (variedad Cisnes) de baja calidad para la talla (Méndez et al. 2012). Sin embargo, se observa una preferencia por rocas basálticas y andesíticas. Por otro lado, se identifica una mayor variación en cuanto a las características de los soportes. El volumen de las piezas es mayor en relación con los otros métodos definidos, con un promedio de $235,5 \mathrm{~cm}^{3}$ y valores volumétricos máximos que sobrepasan los $500 \mathrm{~cm}^{3}$ (Fig. 3). Hay una tendencia general hacia la presencia de corteza en los ejemplares, aunque sus porcentajes son variables. En todos los casos, la forma y disposición de los negativos permiten observar atributos del soporte, los cuales permitieron identificar una tendencia excepcionalmente pareja, en el que el $50 \%(n=21)$ de los soportes corresponde a lascas masivas, mientras que el otro $50 \%$ corresponde propiamente a masas centrales sin atributos de lascas masivas. La presencia de lascas masivas denota una elección técnica particular del método de talla de plataforma preferencial. En estas piezas hay un uso recurrente del reverso de las lascas de gran tamaño como plataforma principal de percusión, similar al método unipolar secante sobre positivo definido por Loyola et al. (2018) y al método unipolar secante sobre lasca espesa definido por Morello (2005). En cuanto a la plataforma de percusión, fue posible distinguir dos agrupaciones principales, aquellas piezas que cuentan con una sola plataforma $(88 \% \mathrm{n}=37)$ y, minoritariamente, ejemplares que cuentan con dos a tres $(12 \% \mathrm{n}=5)$.

Se reconoció la aplicación de cuatro técnicas de talla. Primero, en cuanto a la aplicación de la fuerza, si bien se identificó tanto percusión dura como blanda, los ejemplares en su mayoría fueron tallados a partir de percusión dura. Asimismo, se observó la preparación del borde adyacente a la plataforma en seis ejemplares (14,3\%). Por último, el acondicionamiento de las piezas, identificado a partir del tallado paralelo o secante opuesto a la plataforma principal de percusión, se observó en un $31 \%(n=13)$ de los ejemplares. En todos los casos en los que se identificó, las piezas fueron talladas desde una plataforma principal en asociación a una y hasta cuatro extracciones expansivas talladas desde una plataforma secundaria, opuesta a la plataforma principal (Fig. 11). Esta última técnica se estaría realizando con el fin de regularizar la superficie a partir de la cual se sostuvo la pieza.
Del total de piezas talladas según este método, 29 ejemplares (69\%) presentaron recurrentemente huellas macroscópicas como microlascados o bordes esquirlados y redondeamiento de los filos. Estos atributos visibles permiten sugerir que se trataría de daños producto de acciones sobre sustratos duros; en vistas del contexto, se estima que corresponderían a cepillos para acondicionar superficies de madera. En el 58,6\% de éstas, se reconoce como soporte una lasca masiva, mientras que el $41,4 \%$ corresponde a masas centrales.

\section{Distribución de los métodos de talla en los} sitios arqueológicos del valle del río Cisnes

Los sitios residenciales registrados en el valle del río Cisnes son cinco y se ubican, tanto en la cuenca superior, como en la cuenca media del valle (Fig. 2). Los sitios logísticos corresponden a quince sitios ubicados en los tres segmentos del valle, dentro de estos se incluyen cuatro concentraciones discretas definidas como eventos de talla aislados y como artefactos aislados.

\section{(1) Sitios residenciales}

El sitio Appeleg 1 (CIS009) corresponde a una extensa concentración de material arqueológico cuyas edades más confiables posicionan la ocupación humana entre 330500 y 730-800 años cal. AP (Méndez \& NuevoDelaunay, 2019). Se ha definido como el conjunto habitacional de mayor tamaño en el valle (Méndez et al. 2006a). El conjunto lítico observado refleja segmentos de la cadena operativa (Velásquez et al. 2007), a excepción de algunos casos en los que la cadena operativa se identificó de manera completa (Contreras et al. 2016). Principalmente se describe el descarte de instrumentos que ingresaron en un estadio avanzado al contexto y, en menor medida, conjuntos informales de rápido descarte (Andrefsky, 1994, 1998; Velásquez et al. 2007).

Las masas centrales identificadas, en su mayoría, se componen de materias primas de buena calidad (silíceas) y de posible procedencia foránea. Una excepción corresponde a un ejemplar de grano grueso, posiblemente un guijarro recolectado en las inmediaciones del sitio. Es probable que su descarte se deba a que 

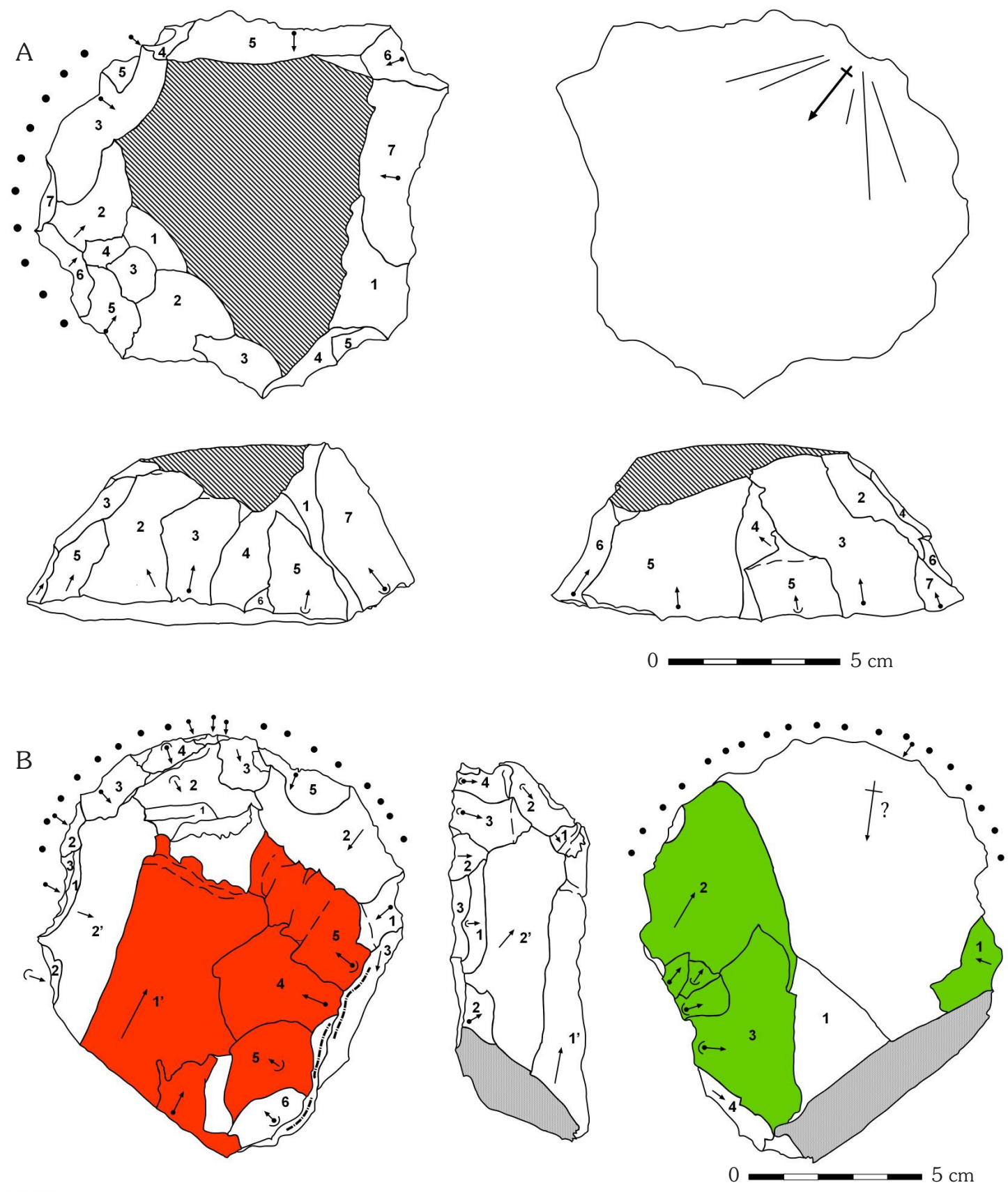

$\bullet \bullet \bullet$ Huellas de microastillamiento

- Dirección de la extracción,

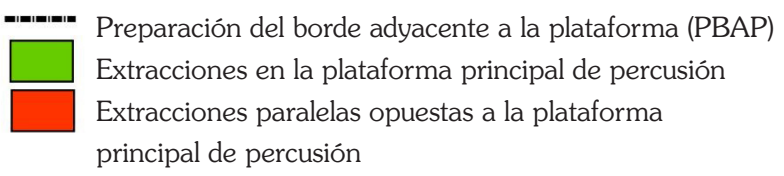
punto indica contrabulbo

Dirección de la extracción

Positivo o reverso de una extracción

principal de percusión

Fig. 11. Piezas talladas según el método de plataforma preferencial, localizadas en el sitio arqueológico El Deshielo (CIS008; estepa). A: lasca masiva con presencia de bordes esquirlados. B: ejemplo de aplicación de la técnica de preparación del borde adyacente a la plataforma, así como la presencia de bordes esquirlados y el uso de más de una plataforma de percusión. 
la pieza respondió a una lógica de talla inicial o de prueba de calidad de la materia prima. Del total de piezas, cuatro se agruparon bajo el método de talla multidireccional, siendo coincidentes sus productos con lo descrito por Velásquez et al. (2007) para el caso del conjunto informal. Consideramos que en la talla de masas centrales se buscó la producción de lascas para múltiples usos, lo que se condice con el conjunto de instrumentos identificados (Contreras et al. 2016). Asimismo, una masa central tallada según el método de tendencia bifacial, cuyos negativos de extracciones fueron poco normados, posiblemente cumplió un rol similar al del método multidireccional descrito.

Appeleg 2 (CIS018), ubicado a 1,9 km del sitio anterior, se define como un sitio residencial de uso breve, en donde destaca igualmente la presencia de conjuntos formales e informales (Méndez et al. 2006a). No posee fechados directos, pero la evidencia sugiere una relativa contemporaneidad con Appeleg 1. La representación del método de talla de plataforma preferencial se observó en un ejemplar de materia prima de buena calidad (silícea). Esta pieza corresponde a un núcleo tallado desde una plataforma principal de manera unidireccional con negativos laminares. Por otro lado, se identificó un ejemplar tallado según el método multidireccional, el cual corresponde a un derivado de una pieza mayor que se continuó tallando una vez fracturada. Ambas piezas se interpretan como núcleos para producir soportes, ya sean formales o informales.

El Deshielo (CIS008) es un sitio expuesto en un área de deflación sobre una terraza alta a 100 $\mathrm{m}$ del margen del río Cisnes; aproximadamente a $9,4 \mathrm{~km}$ de Appeleg 1. Los materiales aparecen en dos concentraciones y se apoyan principalmente sobre la terraza. Las fechas disponibles para los estratos que enmarcan el depósito sugieren una edad del Holoceno tardío para el conjunto (Méndez et al. 2019). Una nueva fecha de 3.011 \pm 28 años AP (D-AMS 027546, carbón, calibrada

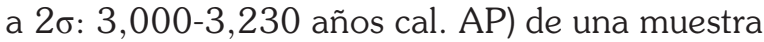
en estratigrafía en el margen del sitio (aunque no registrada directamente en asociación a las piezas), se ajusta con la edad que se presume para el descarte de la mayoría del conjunto. Se registró una gran variedad de categorías morfofuncionales que ilustran la realización de diversas tareas (Tabla 1), caracterizándose como de tipo residencial (Reyes et al. 2006; Méndez et al. 2010). Se ha registrado instrumentos sobre soportes de lascas y láminas, percutores, bolas líticas e instrumentos de molienda, entre otros. Los desechos de talla, sin embargo, son un segmento de la cadena operativa que se encuentra sub-representado (Méndez et al. 2010). La única cadena operativa más completa se observa en la producción de posibles cepillos, lo que sugiere que además se llevaron a cabo tareas específicas. Una gran cantidad de masas centrales $(n=17)$ destaca en este sitio (Fig. 2).

Se observaron los cuatro métodos identificados en elvalle, destacando el método de talla de plataforma preferencial, aplicado en el 76,47\% del conjunto. En los dos ejemplares del método de talla multidireccional observamos una similitud con los registrados en Appeleg 1, ya que la talla apuntó a la producción de lascas como soportes. En una pieza tallada según el método de tendencia bifacial, en la que se identificó un proyecto más planificado, se observaron extracciones laminares paralelas al plano de intersección de las superficies que se corresponde con láminas registradas en superficie. Las piezas multidireccionales, así como el ejemplar de tendencia bifacial, sugieren la intención de producción de lascas y láminas para su uso como soportes.

En cuanto a las piezas talladas según el método de plataforma preferencial $(n=13)$, el $50 \%$ fue manufacturado sobre lascas masivas, mientras que la otra mitad a partir de masas centrales. Con excepción de un ejemplar, todas muestran huellas macroscópicas asociadas a uso, como el redondeamiento de sus filos y micro astillamiento. Por otro lado, se observó un alto porcentaje de acondicionamiento de las piezas, técnica que se registra a partir de la observación de extracciones paralelas o secantes opuestas a la plataforma principal de percusión, posiblemente realizadas con el fin de regularizar la superficie a partir de la cual se sostiene la pieza. La aplicación de esta técnica da cuenta de una mayor preparación del instrumento, concentrándose, en El Deshielo, el 46,2\% de las piezas que presentan esta técnica a nivel de valle.

La presencia de un conspicuo parche de bosque al norte del sitio y la amplia representación del método de plataforma preferencial entre las masas 
centrales, sugieren que estas piezas correspondieron a cepillos utilizados en el aprovisionamiento, descortezamiento y regularización de superficies de madera. A diferencia de lo que se registró en Appeleg 1 , en donde se observaron principalmente lascas y masas centrales para la producción de soportes, en El Deshielo resalta la abundante cantidad de piezas terminadas y descartadas.

El sitio Winchester 1 (CIS077) se ubica en una duna sobre una morrena, en el área de ecotono bosque-estepa. Posee edades que van entre los 680770 años cal. AP (Méndez et al. 2016b). El conjunto lítico registrado incluye raspadores sobre lascas y sobre láminas, hojas y desechos de talla en materias primas silíceas de buena calidad y en rocas locales de grano grueso. Estas evidencias y la presencia de restos de áreas de cocina sugieren una función residencial (Reyes et al. 2007b). En este sitio se identificó sólo una masa central, cuyo soporte corresponde a un guijarro de grano grueso de volumen considerable $\left(400 \mathrm{~cm}^{3}\right)$ tallado según el método de talla de plataforma preferencial. Se observó la extracción de lascas informales posiblemente para el uso de sus filos vivos en tareas diversas. Esta pieza no coincide con las materias primas de las lascas registradas en superficie, lo que sugiere que otras masas centrales fueron retiradas del sitio.

Alero Las Quemas, a diferencia de los anteriores sitios, corresponde a un gran reparo rocoso ubicado en el bosque del curso medio del río Cisnes (Méndez \& Reyes, 2006). El conjunto lítico registrado se compone de derivados de núcleo, desechos de talla, láminas, un raspador, una mano de moler, un núcleo multidireccional y un cepillo de basalto (Méndez et al. 2016a). Análisis funcionales en los filos utilizados sugieren una variabilidad de tareas que incluyó el trabajo sobre sustancias duras, posiblemente hueso y maderas (Hormazábal, 2015). Las dos masas centrales registradas fueron talladas según los métodos de talla multidireccional y de plataforma preferencial (i.e., un cepillo). La pieza multidireccional, por su parte, representa un ejemplo de un núcleo productor de lascas poco normadas.

Sitios de tarea, eventos y artefactos aislados

En los quince sitios de tarea abordados en este estudio, se observa la presencia de todos los métodos de talla identificados en el valle. Once de los quince sitios mencionados corresponden a concentraciones discretas de material lítico, eventos de talla aislados y artefactos aislados en el espacio, emplazados principalmente en el curso superior del río Cisnes, a excepción de un caso identificado en el curso medio.

El Chueco 1 (CIS042) corresponde a un sitio bajo reparo rocoso ubicado en el curso superior del río Cisnes. A partir de las acotadas evidencias registradas a lo largo de su secuencia (11.500 años), se definió como una locación de tareas (Méndez et al. 2011, 2016b). Adscrito al bloque temporal entre los 3.180 y 2.570 años cal. AP se registró una masa central de materia prima de grano medio a grueso trabajada según el método de talla de plataforma preferencial (Reyes et al. 2007a).

El sitio Altos del Moro 2 (CIS079) se ubica en el bosque del curso medio del río Cisnes, a aproximadamente $8,5 \mathrm{~km}$ al sudeste de Alero Las Quemas. Posee una edad de 1.730-2.000 años cal. AP (Thompson \& Méndez, 2019). En cuanto al conjunto lítico, se observa un uso mayoritario de materias primas locales y la representación de las principales etapas de la cadena operativa, lo que sugiere la elaboración y descarte del material lítico de manera local (Thompson \& Méndez, 2019). Una pequeña porción de la muestra corresponde a estadios finales de la cadena operativa en materias primas alóctonas. Al igual que $\mathrm{El}$ Deshielo, presenta un abundante número de masas centrales $(n=15)$, especialmente en comparación con los otros sitios registrados en el valle. Cuatro piezas fueron talladas según el método de tendencia bifacial y seis ejemplares según el método multidireccional. Esto sugiere que en Altos del Moro 2 se buscó la producción de lascas como útiles de filo vivo o formas base. Es posible que los soportes identificados fueran utilizados sobre sustancias duras como madera de manera similar a los registrados en Alero Las Quemas. Por otro lado, se registraron cinco piezas talladas según el método de plataforma preferencial; todas con presencia de huellas macroscópicas atribuibles a uso, posiblemente sobre sustratos duros.

Altos del Moro 1 (CIS081) y Altos del Moro 3 (CIS080) se localizan en la cuenca media del río Cisnes, ubicados a 0,23 km y 2,44 km, respectivamente, al este del sitio Altos del Moro 2 (CIS079). La baja frecuencia de material en los 
dos primeros sugiere que corresponderían a una expresión puntual de lo depositado en Altos del Moro 2, donde se presume una mayor recurrencia (Thompson \& Méndez, 2019). Por otro lado, si bien en Altos del Moro 1 (CIS081) se identificaron sólo piezas talladas según el método de plataforma preferencial $(n=4)$, el resultado buscado en algunas piezas fue la producción de soportes (lascas), mientras que en otras, fue la elaboración de instrumentos sobre masas centrales. Por lo tanto, el énfasis detrás de la talla sería similar a los descritos en Altos del Moro 2 y Altos del Moro 3.

Alero El Toro corresponde a un sitio de tareas bajo reparo rocoso, ubicado en bosque siempreverde del curso inferior del río Cisnes (Bate \& Mena, 2005). Se ha interpretado como un contexto de uso recurrente, pero de poca intensidad, con edades promediadas entre 2.360 y 2.700 año cal AP. (Méndez et al. 2016a). En cuanto a los conjuntos líticos, se observaron dos estrategias, por un lado, una conservada como lo atestiguan abundantes desechos bifaciales sobre materias primas alóctonas, que representan estadios finales de la cadena operativa, $y$, por otro lado, una estrategia de uso de materias primas locales, de rápido descarte y baja inversión energética (Méndez et al. 2006b). Al igual que en Altos del Moro 2, vemos representados tres métodos definidos para el valle del río Cisnes: el de tendencia bifacial $(\mathrm{n}=2)$, el multidireccional $(\mathrm{n}=2)$ y el de plataforma preferencial $(n=8)$. En este último, tres ejemplares presentan huellas atribuibles a uso. Para aquellas piezas donde no se observó signos de uso, se propone que fueron conceptualizadas a modo de núcleos para la producción de soportes. Por otro lado, a partir de la morfología poco extensiva de las extracciones y la presencia de terminaciones en bisagra, dos piezas corresponderían a instrumentos de corte por percusión elaborados sobre guijarros (Méndez et al. 2006b). Sobre la base de la información observada en las masas centrales, proponemos un énfasis direccionado hacia la tarea de obtención de materias primas madereras.

Entre las concentraciones discretas de material lítico, los eventos de talla aislados y artefactos aislados; los sitios CIS090, CIS069, Dolly (CIS098), Barrancas Cisnes (CIS085) y CIS056, presentaron ejemplares que fueron tallados según el método de plataforma preferencial. De éstos, todos a excepción de un ejemplar identificado en CIS056, presentan huellas marginales atribuibles a uso como las descritas en casos anteriores. El caso particular de CIS056 corresponde a un evento aislado de talla, en donde un núcleo agotado fue registrado en asociación a sus desechos de talla. Por otro lado, Barrancas Cisnes 2 (CIS087), Estero La Barranca -2 (CIS020) y CIS040 son sitios en los que se observaron ejemplares del método de talla multidireccional, vinculados a actividades de carácter logístico en los que se buscó la producción de soportes. El artefacto aislado Río Moro fue tallado según el método de tendencia bifacial, se emplaza en el curso medio del río Cisnes. Finalmente, en el sitio Bloque Los Patos (CIS012), se registra una masa central tallada según el método de talla inicial, posiblemente descartada producto de restricciones de calidad de la materia prima.

\section{DISCUSIÓN}

Para el valle del río Cisnes, se ha propuesto que el método de tendencia bifacial fue la principal respuesta a la producción de lascas y láminas con el fin del uso de sus filos vivos y como soportes para la confección de instrumentos. En general la morfología de las extracciones es poco normada, por lo que se sugiere que se priorizó la obtención de lascas de filos vivos y de soportes para instrumentos formales, a excepción de una única pieza en la que se observa uso de percusión blanda, posee extracciones laminares y se compone de materia prima silícea de buena calidad. El 77,8\% de las piezas talladas según el método de tendencia bifacial se localiza en sitios de tarea.

El método de talla multidireccional, al igual que el de tendencia bifacial, buscó la producción de lascas y láminas para usos diversos. Un $60 \%$ se registró en sitios de tarea y un $40 \%$ en sitios residenciales. En los sitios de tarea este método se distribuye en seis sitios, entre los cuales Altos del Moro 2 (CIS079) concentra la mayor frecuencia de piezas talladas según este método (50\%). En cambio, en los sitios residenciales se identificó en cuatro de los cinco sitios registrados en el valle.

En cuanto al método de plataforma preferencial, el 59,5\% de las piezas se ubica en locaciones de tarea, resumidas en un total de diez 
sitios. De estas piezas, un $64 \%$ presenta huellas macroscópicas atribuibles a uso. En cambio, el otro $40,5 \%$ del método de talla de plataforma preferencial se identificó en los cinco sitios residenciales registrados en el valle, en donde el $76,5 \%$ presentó huellas de uso (Fig. 2).

\section{El façonnage versus el debitage}

Uno de los puntos centrales de este trabajo fue abordar la dicotomía aparente producida por la división arbitraria que se realiza entre núcleos $e$ instrumentos. Pese a que esta segregación tiene larga data en arqueología, los criterios utilizados rara vez han sido especificados (Belfer-Cohen \& Grosman, 2007). Ya que nuestras observaciones e interpretaciones dependen del rango de categorías que tenemos en mente, las implicancias de esta división son complejas en tanto adelantan posibles conclusiones que se desprenden de la concepción de estas categorías inicialmente separadas (Dibble $\&$ McPherron, 2007). Si bien es necesario clasificar para ordenar la información observada, consideramos que la diferenciación entre núcleos $e$ instrumentos puede realizarse como producto de una revisión acabada de las piezas y la comprensión de los proyectos de la talla lítica, y no como un paso inicial basado en aspectos morfofuncionales.

El 46,7\% de las masas centrales del Cisnes fue trabajado según un esquema de façonnage y principalmente se talló a partir del método de talla de plataforma preferencial. Los ejemplares que siguieron un esquema de debitage (53,3\%), presentan una tendencia a extracciones de mayor tamaño en comparación con el façonnage, siendo reconocidas las extracciones marginales sólo en el caso de tres ejemplares (7,5\%). Esto contrasta con las piezas de un esquema de façonnage, entre las cuales destaca la presencia de extracciones marginales (40\%) en combinación con extracciones de otras extensiones.

El $60 \%$ de las piezas trabajadas por façonnage fueron talladas a partir de una lasca masiva que sirvió de soporte, mientras que el $40 \%$ restante se talló desde guijarros o nódulos que naturalmente presentaban superficies planas en alguna de sus caras. En el caso de las lascas masivas, esto no sólo implicó la elección de un soporte ideal, sino también una intención de producir el soporte a partir del cual se elaboraría el instrumento. En el caso del façonnage, los instrumentos se fracturan y descartan sobre soportes de gran tamaño, a diferencia de los ejemplares de debitage. El volumen más acotado de los últimos, responde a un mayor agotamiento del nódulo debido a que el proyecto buscó la extracción de la materia prima. Al contrario, el gran tamaño de las piezas de façonnage se vincula con los requerimientos del trabajo sobre maderas, así como su rápido descarte ante el acelerado consumo de filos que produce esta actividad (Hayden, 1978).

Sólo en tres ejemplares se registraron acciones en las que se articuló tanto debitage como façonnage. A partir de estas masas centrales vemos cómo una misma pieza puede ser tallada bajo diferentes métodos durante su vida útil. La última función que cumplieron fue la de un cepillo, pudiendo haber cumplido otros posibles roles. Corresponden a cepillos sobre núcleos prismáticos que se identifican en diferentes áreas de Patagonia $y$ el noroeste argentino, en los que se reconoce que, una vez cumplida su función como núcleo de extracción de lascas, la pieza cambió a una forma base para la confección de un instrumento (Aschero, 1983).

La distribución espacial de los métodos de talla y el uso del valle

Al observar la localización del registro arqueológico en el valle del río Cisnes es evidente la distribución dispar de las ocupaciones registradas entre ambientes abiertos y cerrados (Reyes et al. 2009; Méndez et al. 2016b). La menor intensidad de ocupación de ambientes cerrados, si bien puede deberse a la dificultad de interceptar sitios en zonas de bosque en comparación con la mayor visibilidad de la estepa, creemos también se relaciona con decisiones humanas en torno al uso del espacio (Méndez \& Reyes, 2015). Se ha caracterizado al valle del río Cisnes como un área geográficamente marginal donde el registro arqueológico se comportaría de forma similar a las estepas abiertas orientales, sólo que en frecuencias decrecientes que se interpretan como una menor intensidad (Borrero \& Muñoz, 1999; Borrero, 2004; Méndez \& Reyes, 2008; Belardi et al. 2010; Méndez et al. 2016a). A escala del valle del río Cisnes, los resultados obtenidos sugieren que, a pesar 
de registrarse una menor intensidad de ocupación en las áreas de bosque, la frecuencia absoluta de masas centrales es bastante similar a la identificada en la estepa; no obstante, a nivel del sitio arqueológico, la frecuencia de piezas por sitio es mayor en los bosques que en la estepa. Esta distribución de piezas se relaciona con las características ecológicas del medio y la disponibilidad de recursos boscosos. Por ejemplo, en el sitio El Deshielo en el Alto Cisnes, se observa en la actualidad un parche boscoso en su entorno, aun estando en un piso vegetacional de estepa. Este contexto incluye conjuntos atribuibles a una ocupación de características residenciales, sin embargo, presenta abundantes evidencias relacionadas con el consumo de madera (Méndez et al. 2010; Contreras et al. 2016). Los procesos de formación descritos para este sitio sugieren que es probable un escenario de palimpsesto de múltiples ocupaciones (Méndez et al. 2019). Al igual que en El Deshielo, muchos otros hallazgos (i.e., ocho hallazgos aislados y/o eventos de talla donde se identificó sólo una masa central) de masas centrales se mapean en relación con parches boscosos, especialmente a lo largo del río Cisnes. Estos sitios de tarea se emplazaron en directa asociación con la disponibilidad de recursos de madera, produciendo eventos de aprovisionamiento puntuales y a baja escala.

Los sitios de características residenciales se ubicaron en áreas donde confluyen diversos recursos, en especial, acceso permanente a agua, por lo que se encuentran rodeados de arbustos y ocasionalmente árboles. Corresponden a sitios en los que se realizaron actividades múltiples, como es el caso de Appeleg 1. En él destaca la proporción de masas centrales bajo un esquema de debitage, por lo que el proyecto buscó la obtención de lascas y formas base. La importante frecuencia de desechos de rocas locales basálticas apoya esta idea, aun cuando no ha sido posible registrar todas las masas centrales desde donde se originaron (Méndez et al. 2006a; Contreras et al. 2016). Su ausencia puede atribuirse a un posterior traslado entre campamentos (Morrow, 1996).

El caso de los ambientes cerrados difiere de los ambientes abiertos en tanto las mayores frecuencias de piezas se observaron en los sitios de tarea. Esto tiene directa relación con la ubicuidad de recursos boscosos en el área, donde la disponibilidad de materias primas no es un factor determinante. En este contexto, se identificó una diferencia entre etapas del trabajo de la madera, conceptualizadas como una cadena operativa con distribución diferencial en el espacio. Por una parte, la localización de sitios de tarea, como los contextos de Altos del Moro (CIS 079, 080, 081) o Alero El Toro, caracterizados por abundantes instrumentos masivos como cepillos manufacturados dentro de un esquema de façonnage, se organizó en relación con la disponibilidad del recurso, llevándose a cabo tareas de aprovisionamiento inicial y regularización de superficies. Por otra parte, en sitios con actividades más diversas, como las registradas en Alero Las Quemas, el trabajo identificado sobre sustancias como la madera se observó a través del daño identificado en lascas de filo vivo producidas a partir del debitage (Hormazábal, 2015; Méndez et al. 2016a).

\section{CONCLUSIONES}

La investigación realizada buscó analizar un conjunto de evidencias líticas para comprender la forma cómo se configuró la tecnología de talla en función del uso del espacio del valle del río Cisnes. A partir de un análisis centrado en los métodos de talla de las piezas líticas, fue posible abordar conjuntos obtenidos en sitios que difieren tanto en la localización y recursos a los que están asociados, como en cuanto a las funciones que éstos cumplieron en el asentamiento del valle. Sobre la base de las hipótesis planteadas, se buscó identificar cuáles variables determinaban la articulación de los métodos de talla y el espacio. A partir de los 3.000 años cal. AP en adelante, se observó las mismas formas de tallar las masas centrales a lo largo de todo el valle del río Cisnes. Los métodos de talla identificados: de tendencia bifacial, multidireccional y de plataforma preferencial, se distribuyen de manera homogénea en el espacio, presentando diferencias en cuanto a su frecuencia. En ambientes abiertos, el método de tendencia bifacial sólo se identificó en los sitios residenciales; mientras que en los ambientes cerrados, sólo se registró en los sitios de tarea, invirtiéndose su frecuencia. Sin embargo, en la estepa hay más sitios residenciales y en los bosques dominan los sitios logísticos, apoyando la idea de una distribución primariamente homogénea. En el caso del método multidireccional y de plataforma 
preferencial, se observó una mayor frecuencia en sitios de características residenciales de ambientes abiertos, en cambio, en los ambientes cerrados la mayor frecuencia de ambos se identificó en los sitios de tarea. En otras palabras, la variabilidad no es suficiente como para plantear diferencias de elecciones tecnológicas explicadas por el tipo de sitio o por su localización a lo largo del valle; sino más bien las distintas formas de talla operaron de manera común a lo largo del área de estudio.

Por otro lado, a excepción del sitio El Deshielo (CIS008), en los sitios residenciales predomina el debitage por sobre el façonnage. Los sitios de las estepas presentan indicadores que sugieren que la organización de la tecnología integró soluciones diversas, las cuales se interpretan como una complementación entre distintas actividades. El descarte de mayor variabilidad de materias primas, cadenas operativas más completas, mayor variabilidad de clases artefactuales, implementos de piedra pulida, en conjunto con las masas centrales, sugieren el dominio de sitios residenciales. En cambio, en los bosques primaron indicadores como la presencia de herramientas sobre masas centrales talladas según el método de plataforma preferencial, interpretadas como cepillos, que responden a estrategias de carácter más logístico. Se interpreta que estas herramientas estuvieron orientadas a actividades como la adquisición de maderas, que dominaron en sitios específicamente orientados al cumplimiento de esta tarea. Incluso, si bien el registro de Alero Las Quemas figura como un sitio de características residenciales, su acotado registro lo sitúa como un sitio de residencia vinculado a las tareas logísticas de los alrededores (Méndez et al. 2016a; Thompson \& Méndez, 2019). En el caso de la estepa, tareas específicas como el aprovisionamiento de maderas, fueron realizadas desde algunos de los sitios residenciales.

Sobre la base de los resultados de este estudio se sostiene que los métodos de talla identificados fueron los mismos para todo el valle (hipótesis nula), por lo tanto, la organización de la tecnología fue común a toda la cuenca. Es decir, no exhibió diferencias significativas en cuanto a tipos/funciones de los sitios o los ambientes donde se emplazaron. Esto apoya la idea planteada anteriormente que propone que el valle del río Cisnes fue usado como un eje a través del cual se movilizaron poblaciones provenientes de la estepa, especialmente durante los últimos 3.000 años (Méndez \& Reyes, 2008; Reyes et al. 2009). En otras palabras, los grupos humanos ocupantes del valle estarían tallando de una misma forma la roca, organizando su tecnología lítica de forma similar durante este período. Cada uno de estos métodos de talla es reflejo de proyectos motivados por la ejecución de una o varias tareas específicas. A partir de la definición de estos métodos se observa que en el valle del río Cisnes hay tres formas particulares de abordar la talla de las masas centrales y éstas responden a diferentes fines. La proporción de estos métodos, vista a través de los productos descartados, permite concluir que una parte significativa de las actividades se definió según la cercanía y condiciones de disponibilidad de árboles y madera, fueran ambientes abiertos (con presencia parchada de bosques) o cerrados. El estudio de los métodos de talla de la tecnología lítica, abordado desde una perspectiva espacial, nos permitió afrontar de manera novedosa las decisiones tecnológicas en el valle del río Cisnes, como ejemplo de la ocupación de distintos ambientes de Aisén continental.

\section{AGRADECIMIENTOS}

Financiado por ANID-FONDECYT \#1210042, \#1180306, Programa Regional CONICYT R17A10002 y National Geographic grant HJ-150R-17. Nuestro agradecimiento a Stephanie Buckaert, al personal de Estancia Río Cisnes, y a Berndt Von Malpaert, por otorgarnos el permiso de acceso a los lugares de trabajo y por su colaboración. Agradecemos por el apoyo en la investigación a Amalia Nuevo Delaunay, Omar Reyes y Juan Bautista Belardi. El apoyo en terreno de Nicolás Sepúlveda y el apoyo editorial de Manuela López Crisosto. Extendemos nuestro agradecimiento al equipo editorial de Magallania y a dos evaluadores anónimos que contribuyeron al manuscrito.

\section{BIBLIOGRAFÍA}

Andrefsky, W. (1994). Raw-material availability and the organization of technology. American Antiquity 59(1), 21-24.

Andrefsky, W. (1998). Lithics: Macroscopic approaches to analysis. Cambridge: Cambridge University Press. 
Aschero, C. A. (1983). Ensayo para una clasificación morfológica de artefactos líticos aplicada a estudios tipológicos comparativos: Apéndice A-C. Cátedra de Ergología y Tecnología. Buenos Aires: Universidad de Buenos Aires.

Bate, F., \& Mena, F. (2005). Alero El Toro: un campamento indígena en el bosque siempreverde cercano al litoral en Aisén. En Museo de Historia Natural de Concepción (Eds.), Actas del XVI congreso nacional de arqueología chilena 2003 (pp. 675-680). Tomé: Escaparate Ediciones.

Belardi, J. B., \& Caracotche, S. (2005). Resultados arqueológicos en el noroeste del lago Viedma, Provincia de Santa Cruz. En Actas del XIII Congreso Nacional de Arqueología. Tomo 4 (pp. 81-88). Córdoba: Editorial Brujas.

Belardi, J. B., \& Carballo, F. (2014). La señal arqueológica del interior del bosque en la margen sur del lago San Martín (provincia de Santa Cruz). Comechingonia Revista de Arqueología 18(2), 181-202.

Belardi, J. B., Espinosa, S., Carballo, F., Barrientos, G., Goñi, R. A., Súnico, A., Bourlot, T... Campan, P. (2010). Las cuencas de los lagos Tar y San Martín (Santa Cruz, Argentina) y la dinámica del poblamiento humano del sur de Patagonia: integración de los primeros resultados. Magallania 38(2), 137-159.

Belfer-Cohen, A., \& Grosman, L. (2007). Tools or cores? And why does it matter: carinated artifacts in Lavantine Late Upper Paleolithic assemblages. In S. P. McPherron (Ed.), Tools versus cores: Alternative approaches to stone tool analysis (pp. 143-163). Newcastle: Cambridge Scholars Publishing.

Bellelli, C., Scheinsohn, V., \& Podestá, M. M. (2008). Arqueología de pasos cordilleranos: un caso de estudio en Patagonia norte durante el Holoceno tardío. Boletín del Museo Chileno de Arte Precolombino 13(2), $37-$ 55.

Bellelli, C., Carballido, M., Fernández, P., \& Scheinsohn, V. (2003). El pasado entre las hojas. Nueva información arqueológica del Noroeste de la provincia de Chubut, Argentina. Werken 4, 25-42.

Bleed, P. (2001). Trees or chains, links or branches: conceptual alternatives for consideration of stone tool production and others sequential activities. Journal of Archaeological Method and Theory 8(1), 101-127.

Böeda, E. (1993). Un mode de production inédit au Paléolithique moyen dans l'industrie du niveau 6e du Pucheuil (Seine-Maritime). Paléo. 5, 111-120. doi : 10.3406/ pal.1993.1106
Böeda, E. (1995). Levallois: a volumetric construction, methods, a technique. En H. Dibble \& O. Bar-Yosef (Eds.), The definition and interpretation of Levallois technology (pp. 41-68). Madison: Prehistory Press.

Bordes, F. (1961). Typologie du paléolithique ancien et moyen. Bordeaux: Delmas.

Borrazzo, K. (2006). Tafonomía lítica en dunas: una propuesta para el análisis de los artefactos líticos. Intersecciones en Antropología, 7, 247-261.

Borrero, L. A. (2004). The archaeozoology of andean "dead ends" in Patagonia: living near the continental ice. In M. Mondini, S. Muñoz \& S. Wickler (Eds.), Colonisation, Migration and Marginal Areas, A zooarchaeological approach (pp. 55-61). Durham: Oxbow Books.

Borrero, L. A., \& Muñoz, S. (1999). La geografía cultural del sudoeste de Patagonia continental. En L. A. Borrero \& K. Borrazzo (Eds.), Bosques, montañas y cazadores: investigaciones arqueológicas en Patagonia meridional (pp. 7-36). Buenos Aires: CONICETIMHICIHU.

Borrero, L. A., Nuevo Delaunay, A., \& Méndez, C. (2019). Ethnographical and historical accounts for understanding the exploration of new lands: The case of Central Western Patagonia, Southernmost South America. Journal of Anthropological Archaeology, 54, 1-16.

Carballido Calatayud, M. (2001). Conjuntos líticos del ecotono bosque-estepa en la localidad Cholila (Provincia del Chubut). En Arqueología argentina en los inicios de un nuevo siglo, Actas del XIV Congreso Nacional de Arqueología Argentina (pp. 309-318). Rosario: Laborde Editor.

Conard, N.J., Sorressi, M., Parkington, J.E., Wurz, S., \& Yates, R. (2004). A unified lithic taxonomy based on patterns of core reduction. South African Archaeological Bulletin, 59(179), 13-17.

Contreras, C., Méndez, C., \& Reyes, O. (2016). Gestión de recursos y organización espacial de cazadores recolectores en la estepa de los valles de Cisnes y Simpson. Magallania, 44(1), 167-185.

Cotterell, B., \& Kaaminga, J. (2000). Mechanics of preindustrial technology. Cambridge: Cambridge University Press.

De Porras, M., Maldonado, A., Abarzúa, A., Cárdenas, M., François, J., Martel-Cea, A... Reyes, O. (2012). Postglacial vegetation, fire and climate dynamics at central Chilean Patagonia (Lake Shaman, $44^{\circ} \mathrm{S}$ ). Quaternary Science Reviews, 50, 71-85.

De Porras, M., Maldonado, A., Quintana, F. A., Martel-Cea, A., 
Reyes, O., \& Méndez, C. (2014). Environmental and climatic changes in central Chilean Patagonia since the late glacial (Mallin el Embudo, $\left.44^{\circ} \mathrm{S}\right)$. Climate of The Past, 10, 1063-1078.

Dibble, H. L., \& McPherron, S. P. (2007). Truncated-faceted Pieces: Hafting modification, retouch, or cores? In S.P. McPherron (Ed.), Tools versus cores: alternative approaches to stone tool analysis (pp. 75-90). Newcastle: Cambridge Scholars Publishing.

Dincauze, D. (2002). Environmental archaeology. Principles and Practice. Cambridge: Cambridge University Press.

Fernández, P., \& Carballido Calatayud, M. (2015). Armas y presas, técnicas de caza en el interior del bosque patagónico. Relaciones de la Sociedad Argentina de Antropología, XL(1), 279-301.

Fernández, P., Carballido Calatayud, M., Bellelli, C., Podestá, M., \& Scheinsohn, V. (2011). Marcas en la piedra, huellas en la tierra. El poblamiento del bosque del suroeste de Río Negro-noroeste de Chubut. En S. Valverde, G. Maragliano, M. Impemba \& F. Trentini (Eds.), Procesos históricos, transformaciones sociales y construcciones de fronteras. Aproximaciones a las relaciones interétnicas (Estudios sobre Norpatagonia, Argentina y Labrador, Canadá) (pp. 195-221). Buenos Aires: Facultad de Filosofía y Letras, Universidad de Buenos Aires.

García, J. L., Maldonado, A., De Porras, M. E., Nuevo Delaunay, A., Reyes, O., Ebensperger, C. A., Binnie, S. A., \& Méndez, C. (2019). Extensive early deglaciation and paleolake history of the Río Cisnes Ice Lobe, Patagonian Ice Sheet $44^{\circ} \mathrm{S}$. Quaternary Research, 91, 194-207.

Garreaud, R. (2009). The Andes climate and weather. Advances in Geosciences, 22, 3-11.

Hayden, B. (1978). Snarks in Archaeology: or, inter-assemblage variability in lithics (a view from the Antipodes). En Dave L. Lewis (Ed.), Lithics and subsistence; the analysis of stone tool use in prehistoric economies (pp. 179198). Nashville: Vanderbilt University Publications in Anthropology 20.

Holdaway, S., \& Stern, N. (2004). A Record in Stone: The Study of Australia's Flaked Stone Artefacts. Canberra: Aboriginal Studies Press.

Hormazábal, N. (2015). Uso de recursos boscosos en el valle del río Cisnes $\left(\sim 44^{\circ} \mathrm{S}\right)$ durante los 3.000-2.300 años cal. AP: una aproximación traceológica (Memoria de título). Santiago: Universidad de Chile.

Inizan, M., Reduron-Ballinger, M., Roche, H., \& Tixier, J. (1999). Technology and Terminology of Knapped
Stone. Nanterre Cedex: CREP.

Loyola, R., Cartajena, I., Núñez, L., \& López, M. (2018). Moving into an arid landscape: lithic technologies of the Pleistocene-Holocene transition in the high-altitude basins of Imilac and Punta Negra, Atacama Desert. Quaternary International, 473(B), 206-224.

Luebert, F., \& Pliscoff, P. (2006). Sinopsis bioclimática y vegetacional de Chile. Santiago: Editorial Universitaria.

Mena, F. (1983). Excavaciones Arqueológicas en Cueva Las Guanacas (RI-16) XI Región de Aisén. Anales del Instituto de la Patagonia, Serie Ciencias Sociales, 14, 67-75.

Mena, F. (1992). Mandíbulas y Maxilares: un Primer Acercamiento a los Conjuntos Arqueofaunísticos del Alero Fontana (RI-22; XI Región). Boletín del Museo Nacional de Historia Natural, 43, 179-191.

Méndez, C., \& Reyes, O. (2006). Nuevos datos de la ocupación humana en la transición bosque estepa en Patagonia: alero Las Quemas (comuna de Lago Verde, XI región de Aisén). Magallania, 34(1), 161-165.

Méndez, C., \& Reyes, O. (2008). Late Holocene human occupation of the Patagonian forests: a case study in the Cisnes river basin. Antiquity, 82, 560-570.

Méndez, C., \& Reyes, O. (2015). Archaeology near the southern Ice-End. Current advances in human interdisciplinary research at central Western Patagonia. SAA Archaeological Record, 15(3), 21-26.

Méndez, C., \& Nuevo-Delaunay, A. (2019). Evidencias a cielo abierto para discutir superficies potenciales de actividad temprana en Patagonia Centro Occidental (44-45 S). Magallania, 47(1), 105-116.

Méndez, C., Reyes, O., \& Velásquez, H. (2006a). Tecnología lítica en el alto río Cisnes (estepa extra-andina de la región de Aisén): primeros resultados. Boletín Sociedad Chilena de Antropología, 39, 87-102.

Méndez, C., Velásquez, H., Reyes, O., \& Trejo, V. (2006b). Tras los moradores del bosque conjuntos arqueológicos de alero El Toro (valle del río Cisnes, XI Región de Aisén). Werken, 8, 101-115.

Méndez, C., Reyes, O., Nuevo Delaunay, A., \& Contreras, C. (2010). Criterios para evaluar ocupaciones tempranas en sitios arqueológicos superficiales, Aisén Norte, Chile. En Arqueología Argentina en el Bicentenario de la Revolución de Mayo, XVII Congreso Nacional de Arqueología Argentina, Tomo 1 (pp. 85-90). Mendoza: Facultad de Filosofía y Letras, Universidad Nacional de Cuyo.

Méndez, C., Reyes, O., Nuevo Delaunay, A., Trejo, V., Barberena, R., \& Velásquez, H. (2011). Ocupaciones 
humanas en el margen occidental de Patagonia Central: eventos de poblamiento en alto río Cisnes. Magallania, 39(2), 223-242.

Méndez, C., Stern, C. R., Reyes, O., \& Mena, F. (2012). Early Holocene long-distance obsidian transport in CentralSouth Patagonia. Chungara, Revista de Antropología Chilena, 44(3), 363-375.

Méndez, C., Reyes, O., Nuevo Delaunay, A., Trejo, V., \& Velásquez, H. (2016a). Alero Las Quemas, a key site for the study of human occupations of Andean Forest in Patagonia (Aisén, Chile). Latin American Antiquity, 27(2), 207-226.

Méndez, C., De Porras, M. E., Maldonado, A., Reyes, O., Nuevo Delaunay, A., \& García, J. L. (2016b). Human effects in Holocene Fire dynamics of Central Western Patagonia ( $44^{\circ} \mathrm{S}$, Chile). Frontiers in Ecology and Evolution, 4, 100.

Méndez, C., Nuevo Delaunay, A., Reyes, O., Ozán, I. L., Belmar, C., \& López, P. (2018). The initial peopling of Central Western Patagonia (southernmost South America): late Pleistocene through Holocene site context and archaeological assemblages from Cueva de la Vieja site. Quaternary International, 473 (B), 261-277.

Méndez, C., Nuevo Delaunay, A., Reyes, O., Maldonado, A., \& García, J.L. (2019). A systematic strategy for assessing the early surface archaeological record of continental Aisén, Central Western Patagonia. In R. Suárez \& C. Ardelean (Eds.), People and Culture in Ice Age Americas, New Dimensions in Paleoamerican Archaeology (pp. 34-51). Salt Lake City: The University of Utah Press.

Morello, F. (2005). Tecnología y métodos para el desbaste de lascas en el norte de Tierra del Fuego: los núcleos del sitio cabo San Vicente. Magallania, 33(2), 29-56.

Morrow, T. (1996). Lithic refitting and archaeological site formation processes. A case study from the Twin Ditch site, Greene County, Illinois. In G. Odell (Ed.), Stone Tools: Theoretical insights into human prehistory (pp. 345-373). New York: Plenum Press.

Niemeyer, H., \& Cereceda, P. (1984). Geografía de Chile. Santiago: Instituto Geográfico Militar.

Odell, G. (1994). Assessing hunter gatherer mobility in the Illinois Valley: exploring ambiguous results. In P. Carr (Ed.), The organization of North American Prehistoric chipped stone tool technologies (pp.
70-86). Ann Arbor: International Monographs in Prehistory.

Pigeot, N. (2003). La economía de la talla de la piedra. Cazadores recolectores de Ponsonby (Patagonia Austral) y su Paleoambiente desde VI al III milenio a.C. Magallania, tirada especial, 31, 117-164.

Quintanilla, V. (1984). Biogeografía. Geografía de Chile. Santiago: Instituto Geográfico Militar.

Reyes, O., Méndez, C., Velásquez, H., \& Trejo, V. (2006). Distribuciones espaciales y contextos arqueológicos de cazadores recolectores esteparios en alto río Cisnes (XI Región de Aisén). Magallania 34(2), 75-90.

Reyes, O., Méndez, C., Trejo, V., \& Velásquez, H. (2007a). El Chueco 1: un asentamiento multicomponente en la estepa occidental de Patagonia Central (11.400 a 2.700 años cal. AP $44^{\circ}$ S). Magallania, 35(1), 107 119.

Reyes, O., Méndez, C., Velásquez, H., \& Trejo, V. (2007b). Ocupaciones humanas tardías en la transición bosque estepa: la localidad de Winchester (curso alto del río Cisnes, Región de Aisén). Magallania, 35(2), 145-150.

Reyes, O., Méndez, C., Maldonado, A., Velásquez, H., Trejo, V., Cárdenas, M., \& Abarzúa, A. (2009). Uso del espacio de cazadores recolectores y Paleoambiente Holoceno en el valle del río Cisnes, Región de Aisén, Chile. Magallania, 37(2), 7-23.

SERPLAC. (2005). Atlas de la región de Aisén. Santiago: Ministerio de Planificación y Cooperación, Lom Ediciones.

Thompson, B. (2016). Métodos de talla de masas centrales en el valle del río Cisnes: una aproximación a la distribución de las actividades desde el material lítico. (Memoria de título). Santiago: Universidad de Chile.

Thompson, B., \& Méndez, C. (2019). Altos del Moro 2: una ocupación a cielo abierto ca. 2.000 años cal. AP en los bosques occidentales de Patagonia Central. En P. Andrade \& K. Vargas (Eds.), Actas del XX Congreso Nacional de Arqueología Chilena (pp. 249-260). Universidad de Concepción.

Velásquez, H., Méndez, C., Reyes, O., Trejo, V., Sanhueza, L., Quiroz, D., \& Jackson, D. (2007). Campamentos residenciales tardíos a cielo abierto en el alto río Cisnes (Región de Aisén): Appeleg 1 (CIS 009). Magallania, 35(1), 121-132. 